\title{
Sustainability Research Project: Research of Suitable Locations, Design and Operation of Microalgae Production Plants for Biofuel's
}

\author{
Peter Dalgleish \\ RMIT University, Melbourne, Australia \\ Email: pdalgleish@swin.edu.au
}

How to cite this paper: Dalgleish, P. (2017) Sustainability Research Project: Research of Suitable Locations, Design and Operation of Microalgae Production Plants for Biofuel's. Natural Resources, 8, 671-708. https://doi.org/10.4236/nr.2017.811043

Received: June 5, 2017

Accepted: November 27, 2017

Published: November 30, 2017

Copyright $\odot 2017$ by author and Scientific Research Publishing Inc. This work is licensed under the Creative Commons Attribution International License (CC BY 4.0).

http://creativecommons.org/licenses/by/4.0/

\begin{abstract}
One of the most damaging of these environmental issues is the use of fossil fuels resulting global warming due to the release of carbon dioxide $\left(\mathrm{CO}_{2}\right)$ into the atmosphere. The world's dependency on fossil fuels has also led to depleting supplies creating a need to develop alternative energy sources. Fossil fuels are used to supply energy for many applications such as industry and farming but the use of fossil fuels for transport is by far the most extensive.
\end{abstract}

\section{Keywords}

Suitable Locations, Design and Operation, Microalgae Production Plants

\section{Introduction}

Since the beginning of the industrial revolution many environmental issues have started emerging due to the growing human dependency manufactured items, transport and the constant desire to increase personal wealth. The result is a lifestyle that puts great pressure on our planets environment and ecosystem creating changes so vast that the very ability of the life on the planet to survive is being pushed beyond its tolerances.

One of the most damaging of these environmental issues is the use of fossil fuels resulting global warming due to the release of carbon dioxide $\left(\mathrm{CO}_{2}\right)$ into the atmosphere. The world's dependency on fossil fuels has also led to depleting supplies creating a need to develop alternative energy sources. Fossil fuels are used to supply energy for many applications such as industry and farming but the use of fossil fuels for transport is by far the most extensive.

Many alternative energy supplies to fossil fuels are emerging offering great 
potential such as wind, solar, hydro and biofuels. Some of these alternatives are proving to be both viable and practical but a lot more research and work needs to be done by governments and the private sector throughout the world in order to completely address the problem of global warming. Biofuels offer a good alternative as an energy source for transport due to the mechanical aspects being similar to fossil fuel engines meaning the transformation can be easily achieved.

For many years algae has presented itself as a problem in water supplies causing large contamination problems but now it is showing great potential as a feedstock as a biofuel. The cultivation and processing of algae is currently been undertaken by many different research institutes throughout the world. The focus is on different growing conditions and processes, different species, ways of growing and processing algae and development of competitive economic methods of producing algae biofuels. Species of microalgae show the most potential and these species perform well in the natural sunlight of open ponds which is a cheaper way of cultivation and doesn't present the operating challenges of closed systems. Finding ways of harvesting and removing moisture from algae crops is one of the major challenges related to growing algae for biofuels to be overcome. There are many applications for harvesting algae currently utilized but research needs to continue to developing more cost effective techniques.

Algae can be grown in most parts of the world but to produce algae in a financially viable quantity optimum growing locations need to be sourced. Ideally these locations shall have a suitable and reliable water supply, a climate with plenty of year round sunlight and suitable temperatures without sudden fluctuations. Other factors that need to be considered are the availability of local resources, access and transport to the growing location and economic aspects like funding and the political climate and stability of the country.

The construction of an open pond micro algae requires a considerable resources including the acquisition of land, civil engineering construction, hydraulics, filtration, electrical components, electronic control equipment and biological testing equipment. The designer needs to consult with a large amount of professional people from different specialties to achieve a viable working plant. Other factors that need consideration are the availability of infrastructure such as roads to the plant, power supplies and ensuring a suitable constant water supply. The plant needs to be as efficient as possible adopting renewable energy techniques, recycled water supplies and constant monitoring to ensure optimum conditions at all times.

Scope of this Paper

This paper intends to identify some of the world's most suitable locations for microalgae production based on Geographic's, climate and suitable water supply. Other factors to be considered will be the local political circumstances, access and the availability of resources such as materials, labor and expertise. As part of identifying the most suitable locations a brief study description of the life cycle of microalgae shall be included in this paper. This paper shall seek to iden- 
tify three different locations in the world that show potential for microalgae cultivation for biofuel particularly from suitable natural environmental conditions. The intention is to display that these locations can be in from very different parts of the globe but still have some similarities in their climatic, topographic and water supply suitability potential in the production of microalgae. These locations may differ greatly in their economic and political environments which shall also affect their viability for microalgae cultivation for biofuel, but to a lesser extent than the natural environment.

The construction of an open pond microalgae production plant requires in depth research in exploring the feasibility of such a plant to be able to operate in an efficient, cost effective and environmentally responsible manner. To increase efficiency and environmental sustainability of the plant every effort should be taken to maximize available re-newable energy supplies including solar and wind resources. An extensive hydraulic design is essential to maintain adequate water supplies whilst a complex control system is needed to ensure optimum growth conditions at all times. Depending on the location of the plant and the surrounding infrastructure the possibility of using re-cycled water may also be an option. As part of this paper in depth design drawings and specifications shall be undertaken including the construction, hydraulic, electrical, civil, control system and energy supplies. It is the intention of this paper to produce preliminary drawings specifications including costs to help determine the viability of such a project.

\section{Microalgae Biology \& Life Cycle}

In order to locate and build a microalgae plant it is important to understand the biology and lifecycle of different microalgae species to ensure that ideal conditions are maintained and a premium yield is achieved.

Microalgae are one of the oldest life forms on the planet existing for billions of years made up of simple but very effective structure. Microalgae are primitive organisms with a simple cellular structure and a large surface-to-volume-body ratio, which gives them the ability to uptake large amounts of nutrients [1] (Demirbas A. \& F. 2010). Microalgae are very efficient are converting light energy into mass energy and due to their high content of lipids they make an ideal candidate for biofuels. Microalgae are autotrophic microoraganisms having extremely high photosynthetic efficiency and are valued as a rich source of lipids, hydrocarbons, and other complex oils for biodiesel besides being an invaluable source of boiethanol, biomethane and biochydrogen [2] (Singh N. \& Dhar D. 2010). Microalgae have many advantages over other types of algae as they are a very efficient form of converting solar energy into chemical energy and they also have a very high content of lipids (fatty oil) which is a high source of energy. Many algae accumulate substantial amount of non-polar lipids, mostly in the form of TAG or hydrocarbons, and these levels mat reach up to $20 \%-50 \%$ of dry cell weight [3] (Borowitzka M. \& Moheimani N. 2012). 


\subsection{Micro Algae Characteristics}

Algae are a diverse group of organisms known as eukaryotes that have been broken down into two main groups consisting of macoralgae including seaweeds that can grow up to 60 meters in length and microalgae that can be microscopic in size. There are many different genera which are all fast growing, diverse and occur in aquatic areas of both salt and fresh water throughout all parts of the world. Microalgae are everywhere! They occupy virtually every habitat including those with extreme conditions [4] (Seckbach J. 2007).

The microalgae group is believed to contain several thousands of species that have been broken down into main groups based on pigment, life cycle and basic cellular structure. The three most important classes of microalgae in terms of abundance are the diatoms (Bacillariophyaceae), the green algae (Cholorphyceae), and the golden algae (Chrysophyceae) [1] (Demirbas A. \& F. 2010).

Most species of micro algae can be described as autotrophic meaning that they produce food from substances available in their surroundings using light or chemical energy. Autotrophic microalgae can utilize carbon dioxide as the carbon sources and sunlight as the energy source for oil accumulation under special conditions [2] (Singh N. \& Dhar D. 2010). Some microalgae species can be considered hetertrophic organisms which survive by taking in autotrophic organisms to carry out functions for life often resulting in high oil yields. Some autotrophic micro algae can be converted to heteroprophic ones through changing cultivating conditions or using genetic engineering [2] (Singh N. \& Dhar D. 2010).

Many different species of microalgae have been both trialed and utilized in the product of biofuels with new species currently emerging also offering potential. The selection of species is often determined by the existing local conditions and the viable modifications that can be made to the location. Successful microalgae cultivation requires specific environmental conditions, which vary from species to species [2] (Singh N. \& Dhar D. 2010). To date only a small number of microalgae species are in regular cultivation for biofuel use, compared with the thousands of species that exist that may have potential. Currently there are probably no more than about 30 species and genera from no more than 11 taxonomic classes of autotrophic microalgae in use [5] (Posten C. \& Walter C. 2012).

\subsection{Micro Algae Cultivation}

Growing micro algae for biofuels or any other type of energy supply has been occurring for a long time throughout many parts of the world. Renewable energy production from microalgae is not a new concept and has been carried out since the last century [2] (Singh N. \& Dhar D. 2010). The ability of microalgae to efficiently convert energy from the sun combined with its fast growth rate and minimal requirement of land area is well recognized. Microalgae are known to make far more efficient use of solar energy than conventional agriculture and therefore, there has a large potential for biomass production with comparatively 
less land requirements [2] (Singh N. \& Dhar D. 2010).

Cultivating Microalgae is still open to extensive research with trials continuing in many corners of the world. The current extensive research and development activities on microalgae as commercial sources of renewable fuels and energy rely on the basic and applied research on biology, physiology, cultural methods, cultural systems etc undertaken in the past [3] (Borowitzk N. \& Moheimani N. 2012). The oil content of microalgae can be very high which is one of its many features that have attracted scientist and engineers alike to continue research and development of this technology. Oil content of some microalgae can be as high as $90 \%$ of dry biomass weight under extreme growth conditions, and the potential high oil content and dense biomass makes algae an interesting renewable fuel source [6] (Jayaraman S. K. \& Rhinehart R.R. 2015).

The diverse range of microalgae growing conditions and large number of species offers many methods and possible locations to grow microalgae, but to be viable and obtain a highest possible yield the effort must be taken to choose the most productive species whilst maintaining optima conditions to suit that species. The best approach would likely be to screen for highly productive oleaginous strains at selected sites, optimizing growth conditions for large scale culture, and optimizing productivity and lipid production through genetic manipulation or biochemical manipulation of the timing of lipid accumulation in the selected strains [3] (Borowitzka M. \& Moheimani N. 2012). Many different countries in the world have trialed different species of microalgae such as the "Algae Species Program (ASP)" which was launched in the USA in 1980. The ASP program demonstrated that some species of microalgae could be cultivated reliably on a large scale for relatively long periods [3] (Borowitzka M. \& Moheimani N. 2012). Some species of microalgae have shown consistent potential and are considered reliable sources of biofuel. According to Solar Energy Research Institute report, the most promising species for biofuel production are Botryococcus braunii due to its rich quantities of hydro-carbons, Nannochloropsis salina for its high quantities of esters, and Dunaliella salina for its fatty acid content [7] (Gorden R. \& Seckbach J. 2012). See Table 1.

Successful microalgae cultivation requires specific environmental conditions which vary from species to species [2] (Singh N. \& Dhar D. 2010) to achieve Ideal cultivation conditions many factors need to be taken into account. The major parameters influencing biomass production include light of proper intensity and wavelength, temperature, $\mathrm{CO}_{2}$ concentration, nutrient composition, salinities and mixing conditions [2] (Singh N. \& Dhar D. 2010).

In selecting a suitable location to grow microalgae efficiently it is important to take into account light and temperature as being paramount, as creating these conditions artificially can be a very expensive and difficult challenge. Light and temperature are probably most important and well studied factors limiting the lipid and fatty acid composition of algae [3] (Borowitzk M. \& Moheimani N. 2012).

Growing algae for biomass is also becoming useful system for wastewater treatment as the algae captures carbon dioxide, releases oxygen. An emerging 
Table 1. Frequently grown species and oil content.

\begin{tabular}{cc}
\hline Microalgae Species & Oil Content \% by Dry Weight \\
\hline Botryococcus braunii & $25-73$ \\
Chorella sp. & $28-32$ \\
Crpthecodinuim cohnii & 20 \\
Cylindrotheca sp. & $16-34$ \\
Dunaliella primotecta & 23 \\
Isochrysis sp. & $25-33$ \\
Monallanthus saline & 20 \\
Nannochloropsis salina & $31-68$ \\
Neochioris oleoabundans & $35-54$ \\
Nitzschia sp. & $45-47$ \\
Phaeodactylum tricorutum & $20-30$ \\
Schizohytrium sp. & $50-77$ \\
Tetraselmis sueice & $15-23$ \\
\hline
\end{tabular}

Source: Biotechnology Advances 2007.

technology is the use of algal biomass within the wastewater treatment [8] (Bhat N., Panwar A., Bisht T. \& Tamata S. 2014). The use municipal wastewater in microalgae cultivation can not only save water and cost but the water itself my offer some advantages particularly if it is high in nitrogen and phosphors and the production whilst also doubling as a method of wastewater treatment. A great deal of money and effort is being spent on the removal of pollutants such as biochemical oxygen demand, turbidity, nitrogen and phosphorus [2] (Singh N. \& Dhar D. 2010). Algae have been part of the process degrading organic compounds in aerobic water treatment systems along with playing a part in nutrient removal (removal of nitrogen and phosphorus). Wastewater treatment ponds rely on algae photosynthesis to harness sunlight energy and provide oxygen to drive aerobic bacterial degradation of organic compounds [3] (Borowitzka M. \& Moheimani N. 2012). Utilizing algae as part of a water treatment process combined with growing algae as a biofuel feedstock offers a natural solution to two problems in a very environmentally friendly way. The concept of producing biofuel from algae harvested from wastewater treatment HRAP effluent is a niche opportunity that could be economical today [3] (Borowitzka M. \& Moheimani N. 2012).

Some of the advantages of microalgae cultivation include:

- Large amounts of fatty acids

- Very high growth rate

- Thrive in saline water

- Sequester carbon dioxide

- Produce value added co-products or by-products

- Offer multiple crops per year 


\section{Microalgae Cultivation Systems}

There are several different cultivation methods for growing Microalgae, the main ones being an open pond systems, closed systems or hybrid systems. Determining the best system depends largely on the local environment and local weather conditions with regions of high levels of sunlight and warm temperatures offering the best conditions. The most influencing factors of algae growth light intensity, photosynthetic rate, temperature, nutrient availability, and $\mathrm{PH}$ [6] (Jayaraman S. K. \& Rhinehart R. R. 2015).

\subsection{Closed Systems}

Closed systems offer much better environmental control and enables microalgae production to take place in locations a wider range of locations but at a must higher cost in both infrastructure and operational cost. Algae grown in an open system is prone to various environmental uncertainties like temperature fluctuation, weather change, consumption of the nutrients by other organisms in the pond, and stray pathogens [6] (Jayaraman S. K. \& Rhinehart R. R. 2015).

Closed systems (photobioreactors) have been developed recently by the Japanese, French and German governments offering better control of the environment but higher development and operational cost but can return better yields. When designing a photobioreactor, design parameters such as reactor dimension, flow rate, light requirements, cultural conditions, algae species, reproducibility and economic value need to be taken into consideration [1] (Demibras A. \& F. 2010).

\subsection{Open Raceway Pond Systems}

Open raceway pond systems are the cheapest and most productive form of Microalgae cultivation providing ample sunlight and suitable temperatures are available along with a reliable water supply and readily available nutrients. Open pond systems are the oldest and simplest systems for mass cultivation of microalgae [1] (Demirbas A. \& F. 2010). Open pond systems are usually large and shallow with a raceway configuration where paddle wheels keep the algae in circulation. As shown in Figure 1 one of the major advantages to of open pond systems is that they are easier to construct and operate than most closed systems, resulting in a low production and operating cost [7] (Gorden R. \& Seckbach J. 2002). The system is often operated in a continuous mode, i.e. fresh feed is added in front of the paddle wheel, the fresh feed is added in front of the paddlewheel and the algae broth is harvested behind the paddle wheel after it has circulated through the loop [1] (Demirbas A. \& F. 2010). Open pond systems are considered the most efficient and viable methods of microalgae cultivation providing the locations are environmentally suitable. Open culture systems are the main systems used to produce microalgae commercially as well in wastewater treatment systems, mainly because they are the most economical cultural systems for large-scale microalgae culture [3] (Borowitzka M. \& Moheimani N. 2012). 


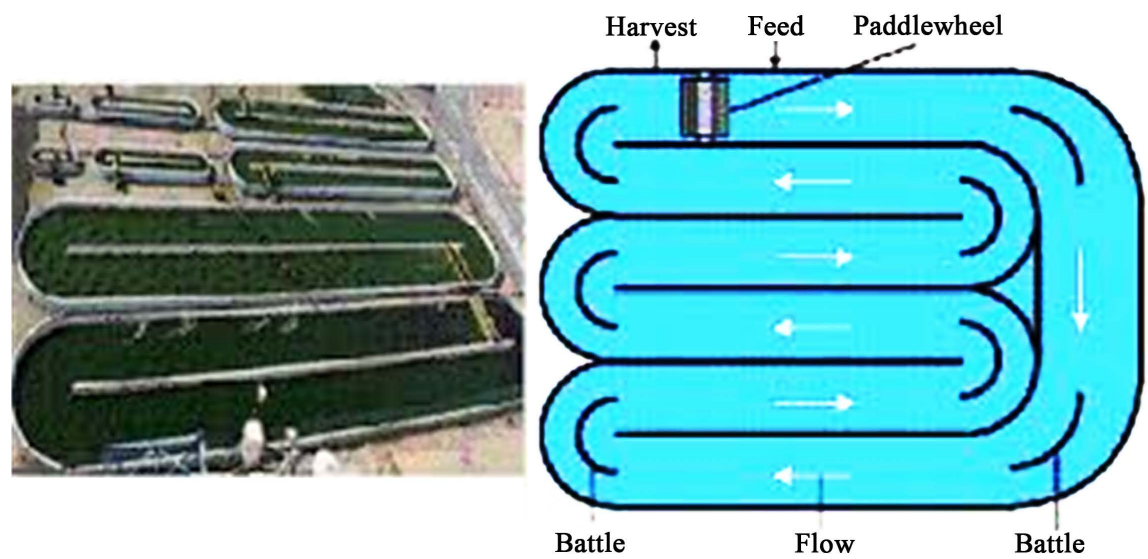

Figure 1. Arial view \& diagram of open pond system.

The scope of this paper shall be dedicated to the cultivation of microalgae in an open pond raceway systems with a high emphasis on optimizing locations and environmental conditions. An attempt will be made to qualify the most viable methods of producing microalgae biofuels based on location and design rather than investigating other methods that require higher investment and operational cost.

\subsection{Components of System}

Some variation in the construction of open pond raceway algae farms can occur the most have the same basic construction components with big variations in size not being uncommon.

Some of the main components include

- Concrete pond structure

- Control System

- Pumping Equipment

- Paddle Wheel Mixing System

- Carbonation Sump

- Instrumentation for Cultivation

- Harvesting System

- Dewatering System

The type and configuration of all components of an open pond raceway system should be subject to in depth research to check compatibility with the other components, availability and the local cultivation systems

\section{Determining the Most Suitable Locations for Microalgae Cultivation}

Growing microalgae for biofuel is not a cheap process and finding the best locations in order to be viable is paramount. Despite algae being very diverse in their ability to grow in a broad range of conditions, locating a microalgae production plant in a location where the natural conditions are most suitable offers many advantages that will result in cost saving and increased viability. Developing a 
mathematical model to determine the optimum growth method and conditions will maximize algae oil production [6] (Jayaraman S.K. \& Rhinehart R. R. 2015). Growing a viable crop requires the combination of selecting the most suitable species to match the best possible location. The first and critical, step in developing a reliable and commercially viable process of producing microalgae for the production of biofuels, or any other product, is the selection of the algae species and strain to be grown [3] (Borowitzka M. \& Moheimani N. 2012).

\subsection{Suitable Light Conditions}

Suitable light conditions are extremely important to algae growth as this forms the major part of their lifecycle. Light is the primary energy source of algae growth. Light intensity varies with the depth of water, and seasonally, and between day-and night [6] (Jayaraman S. K. \& Rhinehart R. R. 2015). Despite high light levels being important to algae growth some disadvantages can occur if light intensity becomes too high. Low light intensity induces the formation of polar lipids, whereas high light intensity with a concomitant increase in the amount of neutral storage lipids, mainly triacylglycerols [9] (Gouveia L. 2011). In microalgae open pond systems, to be viable the selection of a site with substantial amounts of light is preferable, as it is mechanically cheaper and more efficient to reduce light input than needing to create artificial light. In general, microalgae are cultivated in warmer regions of the globe [10] (Abodeely J., Stevens D., Ray A. Schaller K. \& Newby D. 2013).

\subsection{Temperature}

Despite algae naturally occurring in all parts of the world including some of the coldest regions, they have the strongest representation in warmer climates where most species occur reproducing and thriving in warmer waters. Generally, rise in temperature leads to an exponential increase in algae growth until an optimum level is reached, after which growth declines [2] (Singh N. \& Dhar D. 2010). The difference in the reactions of microalgae to temperature changes is quite varied. Some algae have a quite narrow temperature optimum, whereas others can show good growth over a wide temperature range [3] (Borowitzka M. Moheimani N. 2012). When choosing a location for algae cultivation, temperature conditions should be taken into account with a location having temperatures as stable as possible not only from day to night but over seasons. Low temperatures exert an obvious dampening effect on metabolic processes although the magnitude of cold inhabitation varies greatly among species [4] (Seckbach J. 2007). Microalgae growth and biomass production is vulnerable to temperature fluctuations at varied levels. However, it must be recognized that temperature changes not only over the day and from day-to-day, but also with seasons [3] (Borowitzka M. Moheimani N. 2012). Stable night temperatures improve microalgae biomass production due to the balance of night respiration. Respiration during the night leads to biomass loss reducing productivity, and the rate of respiration is affected 
by temperature [3] (Borowitzka M. Moheimani N. 2012). Many other factors temperature control of microlgae in cultivation has other significant affects on biomass production. The major physical stimuli are temperature and light intensity; the former, can modify the fatty acid composition by increasing the unsaturation with the decreasing temperature and vice versa [9] (Gouveia L. 2011).

\subsection{Nutrients}

Nearly all natural water supplies contain some levels of nutrients but to encourage active algal growth often organic and inorganic needed to be added to achieve optimum results. Nutrient availability affects significantly the lipid composition of algae, and a number of broad affects of nutrient limitation have been reported as important modulators of algal lipid biosynthesis [3] (Borowitzka M. Moheimani N. 2012). These nutrients are added in very well balanced, calculated and monitored doses. In open pond designs, nutrients and water are mixed as they enter the ponds [10] (Abodeely J., Stevens D., Ray A. Schaller K. \& Newby D. 2013). Locating an microalgae cultivation plant in a location where waste nutrients are readily available offers both financial and logistic advantages. Wastewater effluent from municipal wastewater treatment facilities can also provide nutrients needed for algae cultivation with supplementation from commercial chemicals [10] (Abodeely J., Stevens D., Ray A. Schaller K. \& Newby D. 2013). Other cheap or easily available sources of nutrients can be sourced from some regions where agricultural activities are present. For additional supplemental nutrients, fertilizer-enriched irrigation runoff from farms can also be used [10] (Abodeely J., Stevens D., Ray A. Schaller K. \& Newby D. 2013).

\subsection{Water Supply}

Water is in abundance throughout many parts of the world, but finding locations with plenty of sunlight and ample water with suitable salt levels is not so common. To provide the algae cultures with enough water for adequate growth, a water source or sources is needed near the designated site that is capable of maintaining a water supply based on the capacity of the algal production system [10] (Abodeely J., Stevens D., Ray A. Schaller K. \& Newby D. 2013). Microalgae can occur in both salt and fresh water usually depending on the species. Microalgae are microscopic photosynthetic organisms that are found in both marine and freshwater environments [1] (Demirbas A. \& F. 2010). Some species of algae have the ability to tolerate a wide range of water salt levels. Some algae exhibit an excellent ability to tolerate high salt concentrations [3] (Borowitzka M. Moheimani N. 2012). Cultivating micro algae can often result in the utilization of water that otherwise has poor potential. One of the important factors that set algae biomass production technology apart from technologies reliant on terrestrial crop production is the ability of algae to utilize water of poor quality, unsuitable for crop production, which usually means brackish and high salinity inland waters and ocean sea waters [11] (Lundquist T., Woertz I., Quinn N. \& Benemann J. 2010). 


\subsection{Renewable Energy Source}

Pumping or moving water is one of the most significant uses of energy in the world today. It is estimated that across a total of three hundred million irrigated hectares globally, 62 TWh is expended annually in pumping irrigation water [12] (UNESCO 2014). Energy can also be a significant cost in running an open pond algae farm with primary energy being pumping and paddle wheel operation which can take place $24 \mathrm{hrs}$ per day. Channel flow velocity is 15 to $30 \mathrm{~cm} / \mathrm{sec}$. Higher velocities require too much energy, at least for biofuels applications [11] (Lundquist T., Woertz I., Quinn N. \& Benemann J. 2010). Building an open pond alga farm in a region where plenty of sunlight occurs, and a reasonable amount of wind is available is desirer able as solar and wind energy offer a cheap carbon neutral alternative. Good opportunity exist to use renewable energy to offset energy supply currently used for pumping, particularly in those pumping applications which are subject to higher prices or in off-grid applications where the cost of pumping is higher [13] (Beca 2015).

\subsection{Environmental Issues}

Any form of industry or agricultural process has some potential environmental issues. Accessing and evaluating these issues is a critical part of an industry such as growing microalgae for biofuel foodstock. One of the intentions of this industry is to minimize environmental damage such as reducing carbon emissions which in turn leads to global warming. This is according to recent report that estimates the world pumped 39.8 billion tons (36.1 metric tons) of carbon dioxide into the air last year by burning coal, oil and gas See Figure 2 [14] (Dailymail 2015). This figure is the result of a very fast growing dependence on fossil fuels that started its rapid climb in the 1950's. See Graph page 23. But care must be taken to ensure that the industry itself does not create its own environmental

$\mathrm{CO}_{2}$ emissions from fossil fuels burning 1751-2012

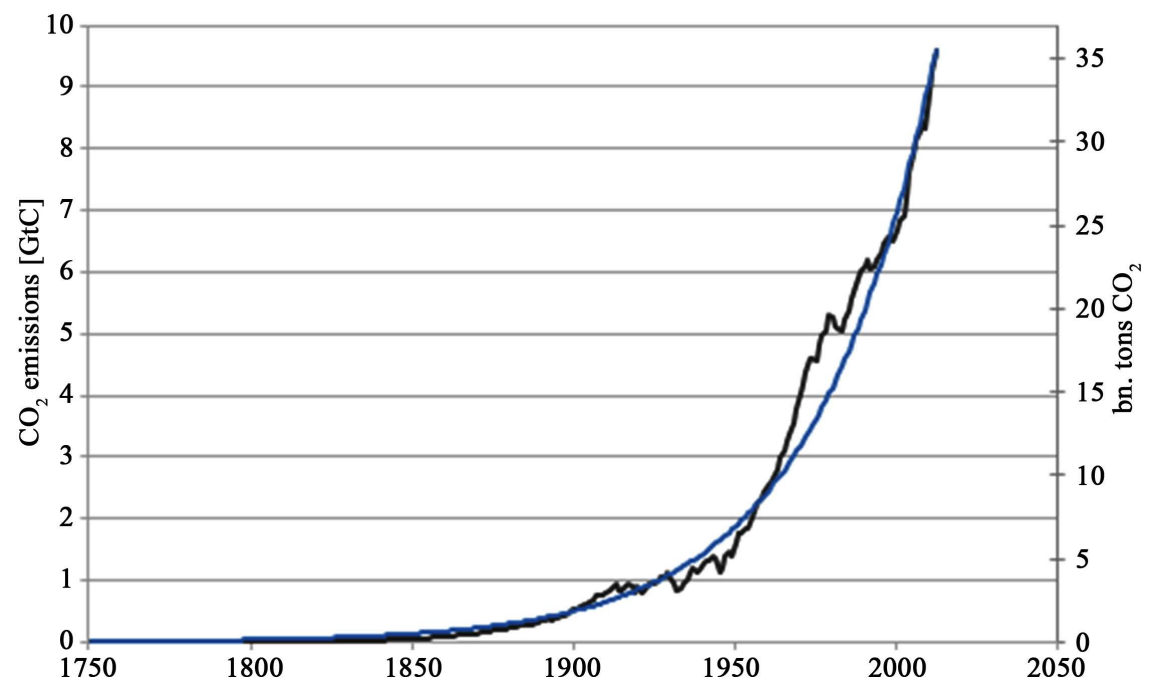

Figure 2. $\mathrm{CO}_{2}$ emissions from fossil fuels burning 1751-2012. 
problems and every attempt must be taken to produce and process microalgae with minimal impact to the local and greater environment. Amongst these cautions the selection of land is vital to ensure land is not used that could be better utilized. To avoid selecting a site with conflicting land use, it was important to identify areas that were not previously developed or used for a more economically viable use [15] (Bortowitza M., Boruff B., Moheinani N., Pauli N., Cao Y. \& Smith H.). As the world's population increases there will be a greater demand for biofuels but also an increased demand for land as food production. Food verses fuel is the dilemma regarding the risk of diverting farmland or crops for liquid biofuel production to the detriment of the food supply on a global scale [1] (Demirbas A. \& F. 2010).

\section{Case Study of 3 Suitable Locations}

As part of the scope of this paper it is the intention to explore some locations that could be considered as highly viable for microalgae biomass cultivation. These locations shall be chosen based on high suitability with focus on the main criteria for microalgae biomass cultivation utilizing an open pond raceway system.

The main criteria include:

- Available natural light levels

- Local temperatures and temperature stability

- Suitable and reliable water supply

- Land availability

- Topography

Many other factors play an important part in the location selection criteria some of which can change frequently such as politics, local economic conditions, availability of expertise and probable regional environmental issues.

Any form of industry or agricultural process has some potential environmental issues. Accessing and evaluating these issues is a critical part of an industry such as growing microalgae for biofuel foodstock. Additional criteria for potential open pond micro algae production systems sites is that the land should be noncompetitive, non-sensitive, and sparsely populated [10] (Abodeely J., Stevens D., Ray A. Schaller K. \& Newby D. 2013). One of the intentions of this industry is to minimize environmental damage such as reducing carbon emissions which in turn leads to global warming. Global climate change is also the major environmental issue of our time [1] (Demirbas A. \& F. 2010). But care must be taken to ensure that the industry itself does not create its own environmental problems and every attempt must be taken to produce and process microalgae with minimal impact to the local and greater environment. Microalgae cultivation for biofuel production can potentially be carried out on marginal land and thus we can reduce the competition for land and may open up new economic opportunities [2] (Singh N. \& Dhar D. 2010). Careful consideration the locations overall potential should be taken before a microalgae production plant is considered. To 
avoid selecting a site with conflicting land use, it was important to identify areas that were not previously developed or used for a more economically viable use [13] (Bortowitza M., Boruff B., Moheinani N., Pauli N., Cao Y. \& Smith H.). As the world's population increases there will be a greater demand for biofuels but also an increased demand for land as food production. Food verses fuel is the dilemma regarding the risk of diverting farmland or crops for liquid biofuel production to the detriment of the food supply on a global scale [1] (Demirbas A. \& F. 2010).

GIS (Graphical Information Systems) is a very useful technology in accessing the most suitable regions for viable microalgae production. More recent GIS-based algal biofuel production facility site targeting includes estimates of production potential [13] (Bortowitza M., Boruff B., Moheinani N., Pauli N., Cao Y. \& Smith H. 2012). This approach has been used widely in the US and other parts of the world with excellent results. The approach focused primarily on the physical characteristics of optimal locations including land-use/ land-cover and slope, and climatic considerations such as insulation, temperature, precipitation and evaporation [13] (Bortowitza M., Boruff B., Moheinani N., Pauli N., Cao Y. \& Smith H. 2012).

The locations chosen for consideration based on the above criteria are:

- Iran's Salt Lake Urmia

- West Australia's Pilbara Region

- USA Salton Sea Lake

\subsection{Brief Description of Iraq's Salt Lake Urmia}

Iran is a very historic country with a very deep culture that lies in the Middle East bordering Iraq, Afghanistan, Pakistan, Turkmenistan and Turkey. Iranians consist of several ethnic groups who have been living peacefully with each other since the beginning of the central government in Iran 550BC, Achaemenians [35] (Iran Geography 2015). Iran has a rapid population growth and despite it having some of the largest gas and oils reserves in the world it is still trying to develop renewable energy sources. Iranian algae biofuel projects is being carries out by researchers iat Tarbiat Modaras University, Tehran and Shiraz University who succeeded in producing green fuel from algae [16] (Najafi G., Ghobadian B. \& Yusaf F. 2011).

Lake Urmia is a salt lake in the North West in Iran which presents itself as an ideal location for a microalgae production plant with many advantages such as suitable water salinity, plenty of sunlight and warm temperatures. See Figure 3. A salt lake in Iran has given rise to a new species of algae for biofuel [16] (Najafi G., Ghobadian B. \& Yusaf F. 2011). Lake Urimia's natural environment is very well suited to microalgae cultivation with algal blooms not being an uncommon occurrence on the region. The "Red Tide" is actually the result of an algal bloom, an event in which marine or fresh water algae accumulate rapidly in the water [16] (Najafi G., Ghobadian B. \& Yusaf F. 2011). 


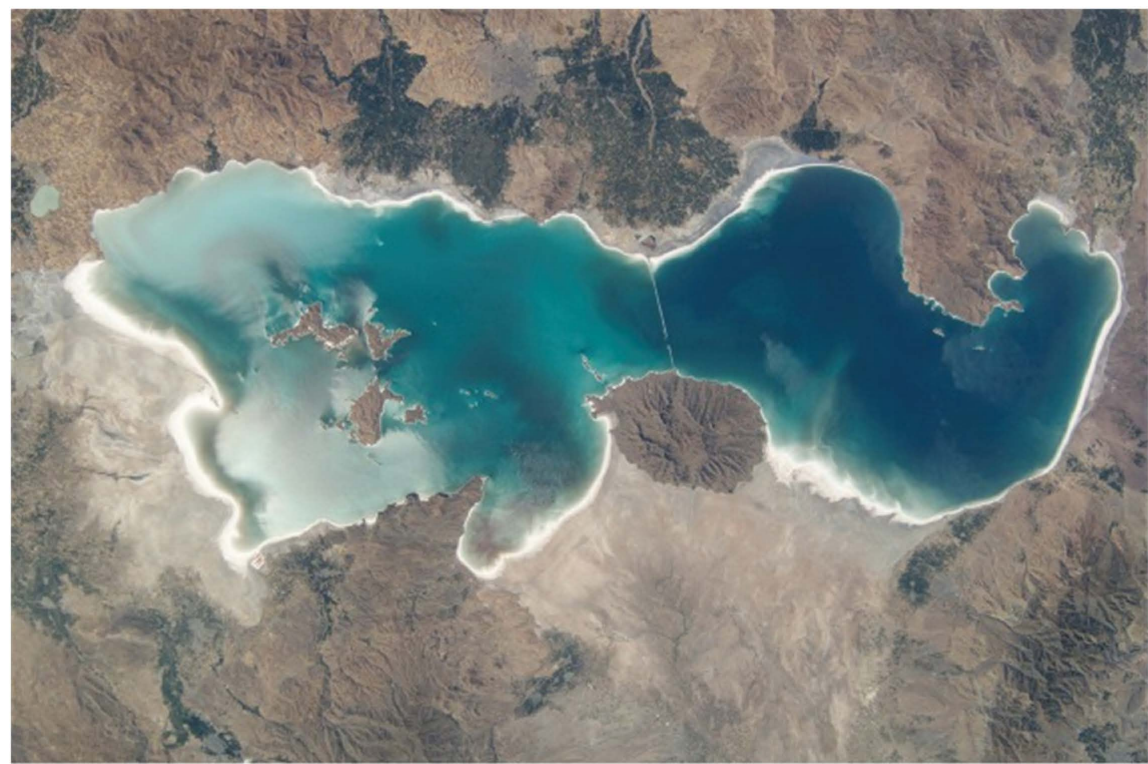

ISS005E10800

Figure 3. Lake Urmia Iran.

\subsection{Brief Description of Western Australia Pilbara Region}

Australia is a very vast land with multiple locations in the North Western corner that could be considered as having the ideal conditions for microalgae biofuel production. Western Australia already hosts the largest commercial microalgae production plant in the world, the Dunaliella salina plant producing the valuable carotenoid B-carotene from this algae [13] (Bortowitza M., Boruff B., Moheinani N., Pauli N., Cao Y. \& Smith H. 2012). This plant is owned and operated by Badishece Anilan-\& Sodafabrik (BASF) since 1989in the Hutt Lagoon Pilbara region of Western Australia for the production of natural food coloring, demonstrating the regions suitability for microalgae production. As shown in Figure 4 Many other locations in the same region offer good potential for the cultivation of microalgae that can be utilized for other applications such as biofuel. Western Australia (WA) specifically, has several key advantages for large-scale microalgae for biofuel cultivation including abundant sunshine, extensive land area unsuitable for agriculture, an abundant water source in the Indian Ocean, existing infrastructure in several potential locations, high local demand for fuel and stable political conditions [17] (Boruff B., Moheimani N. \& Borowitza M. 2015).

\subsection{Brief Description of Salton Sea Lake California}

The USA has many locations that have been identified as potentially viable locations to grow microalgae for biofuel with particular focus on the states from the Pacific Ocean to the Gulf of Mexico. The Salton Sea Lake in Southern California has good environmental, geographical and climatic conditions to suit microalgae cultivation. Over the years the Salton Sea featured in several generic engineering cost analysis, including one that developed cost estimates for a pilot-scale facility and full scale (400 ha) microalgae fuels production on the shores of this lake [31] 


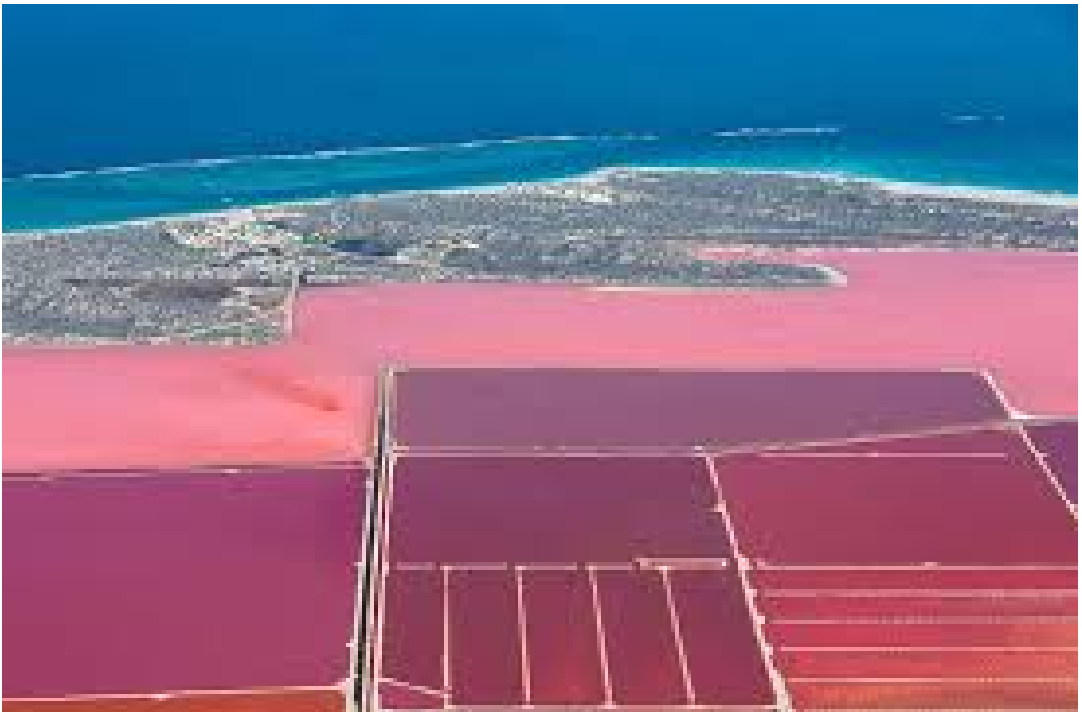

Figure 4. Hutt lagoon microalgae cultivation plant. Source: Lagos Cor de Rosa.

(Gale J. \& Kaya Y. 2003). Salton Sea Lake is suffering from environmental damage as a result of local agriculture and therefore a microalgae cultivation plant could also offer advantages in assisting in water purification. This large (350 mile ${ }^{2}$ ), shallow, inland lake receives about 10,000 tons of nitrogen and phosphorous per year from agricultural drainage waters and other sources, resulting in massive algal blooms, fish kills and other negative environmental impacts. See Figure 5 [18] (Brune D., Yen H., Scharwtz G., Benemann J., Massingill M., Van Olst J. \& Carlberg J. year unkown).

\subsection{Comparing Locations}

The three locations sited as suitable microalgae cultivation sites are in some ways very similar in their positive factors but also have many aspects where they are very different.

Similar Aspects include:

- Within $30^{\circ}$ from the equator

- Plentiful sunlight all year round

- Warm temperatures

- Saline or salty water

- Dry climate but reliable water supply

- Naturally occurring microalgae presence

- Good solar and wind energy potential

- Minor risk to local ecosystem Different Aspects include:

- Local economics

- Transport and accessibility

- Local politics

- Local demand on energy

- Land availability and price 


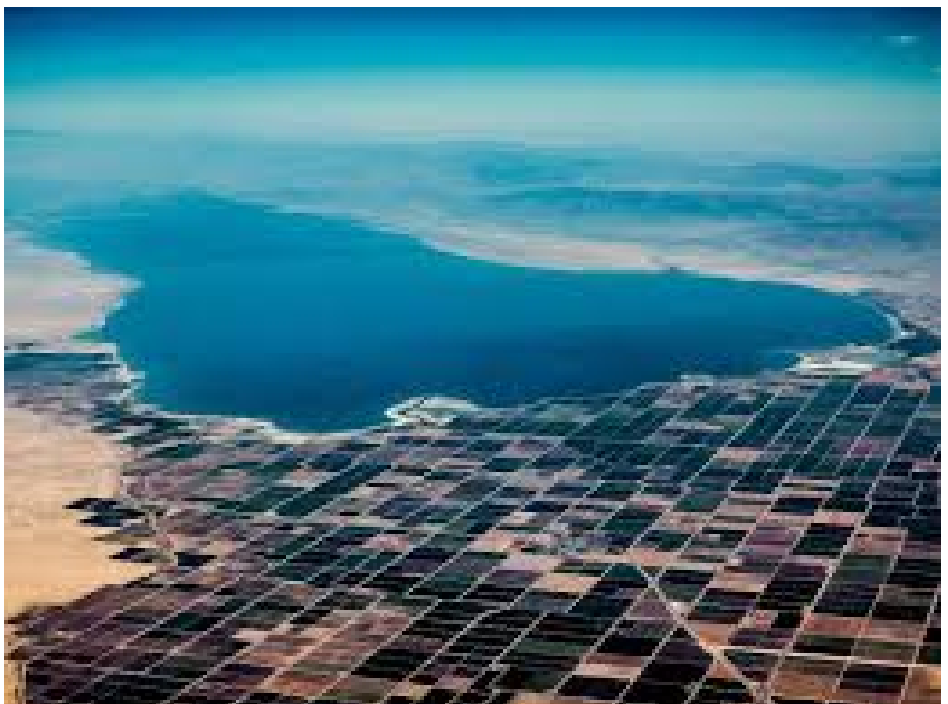

Figure 5. Salton sea California. Source: National geographic.

Lake Urmia Iran has most of the environmental advantages of the other locations but has some risk of the water supply becoming less available. The climate in Lake Urmia's catchment is mainly controlled and affected by the surrounding mountains [19] (Alipour H. \& Tangal Olya H. 2014). This region of Iran has been suffering from drier conditions recently compared to a few decades ago. Because of 10 years of a progressively dry climate in the area, the water level is about $6 \mathrm{~m}$ less than 20 years ago [19] (Alipour H. \& Tangal Olya H. 2014). Some political problems in Iran have affected all aspects of people's day to day life style and business development making it more difficult to attract foreign investment. Currently Iran has economic sanctions that may be lifted in the very near future which may change the economic landscape considerably. The nuclear deal that the U.S. and Europe signed with Iran on July 14 could slowly phase out many economic sanctions, finally allowing western companies to sell their wares in the country and unleashing one of the world's largest untapped markets for Western business [20] (Fortune 2015).

Pilbara Region of Western Australia has many salt lakes and wetlands some of which are close to the coast and some further inland which are subject to reduced water levels or drying up in droughts. The Pilbara has a variety of seasonal intermittent and permanent wetlands [22] (Western Australian Planning Commission 2009). Due to the regions mining industry it offers good infrastructure such as roads and ports with further expansions expected. To meet the export needs of the resource sector, the region's ports are in the process of a major expansion phase, which is anticipated to continue for 5 - 10 years. (Western Australian Planning Commission 2009) Despite the large regional mining industry land is still plentiful and cheap in the Pilbara region due to its vastness. In terms of land requirements, large tracts of level topography with workable soils are important as well as land that can be purchased for a reasonable price [15] (Bortowitza M., Moheinani N., Pauli N., Cao Y. \& Smith H. 2012). 


\section{Salton Sea Lake California}

The Salton Sea offers very high potential for achieving water purification from microalgae while at simultaneously producing microalgae for biofuel due to the large scale agriculture and nutrients runoff in its region. All together, about 35\% of the irrigation water applied to fields in the Imperial and Coachella Valley irrigation districts enters the Salton Sea as agricultural wastewater [21] (Glen E., Cohen J., Morrison J., Valdes-Casillas C. \& Fitzsimmons K. 1999). The viability of a combination a "Partitioned Aquaculture System" (PAS) and a at Salton Lake "Controlled Eutriphication Process" (CEP) appears achievable. Application of the PAS/CEP technology offers potential for demonstration of large-scale microalgae culture for intergrated environment mitigation related to reclamation of municipal solid waste, waste nutrient recovery and, "Greenhouse Gas" GHG reduction [18] (Brune D. Yen H., Scharwtz G., Benemann J., Massingill M., Van Olst J. \& Carlberg J., year unkown). The Salton Sea has a growing environmental issue in salinity build up threatening its viable long term future for microalgae biofuel production. As salinity increases, the reproductive fitness of organisms making up the present food chain will decrease [21] (Glen E, Cohen J, Morrison J, Valdes-Casillas C \& Fitzsimmons K 1999).

\subsection{Selection of Trial Location for Construction and Operating Model}

As part of this paper one of the three locations is to be selected for further study and analysis so that a design and operating cost model can be created. This model can be used as an indicator to determine the viability and problems that may arise in such a project. The selection criteria must take into account all of the influencing factors that may impact on the project helping to determine its chances of successful operation. The influencing factors are of a very broad nature with consideration given to, but not limited to climate, topography, environmental risks, local infrastructure and local political and economic issues. See Table 2.

Table 2. This chart is indicative of conditions only.

\begin{tabular}{|c|c|c|c|c|c|c|}
\hline Location & $\begin{array}{c}\text { Climate } \\
\text { Suitability }\end{array}$ & Topography & $\begin{array}{c}\text { Environmental } \\
\text { Risk }\end{array}$ & $\begin{array}{c}\text { Local } \\
\text { Infrastructure }\end{array}$ & $\begin{array}{c}\text { Political \& } \\
\text { Economic } \\
\text { Stability }\end{array}$ & $\begin{array}{c}\text { Availability } \\
\text { of Local } \\
\text { Waste Water }\end{array}$ \\
\hline $\begin{array}{c}\text { Lake } \\
\text { Urmia Iran }\end{array}$ & Good & Good & Medium & Low & Medium & Low \\
\hline $\begin{array}{c}\text { Pilbara } \\
\text { Region of } \\
\text { Western } \\
\text { Australia }\end{array}$ & Good & Good & Low & Good & Good & Medium \\
\hline $\begin{array}{l}\text { Salton Sea } \\
\text { Lake } \\
\text { California }\end{array}$ & Good & Good & High & Good & Good & High \\
\hline
\end{tabular}

Dalgleish P. 2016. 
The collection of all the data required to fully determine the best trial location is beyond the scope of this paper and the chosen location is based on limited data and the discretion of the writer.

From the information displayed in the above chart and careful consideration of all documented information about each location the writer has chosen the Pilbara Region of Western Australia as the most suitable location for future research, design and operation of a microalgae cultivation for biofuel plant.

\section{Development of Microalgae Biomass Plant in the Pilbara Region}

The Pilbara region Western Australia is a fast area within itself with many possible locations that could be considered as having potential for a viable microalgae biomass cultivation plant. There is also access to an unlimited source of water (Indian Ocean), and Western Australia is one of the sunniest places in the world [15] (Bortowitza M., Boruff B., Moheinani N., Pauli N., Cao Y. \& Smith H. 2012). Many extensive studies of the region have been carried out using GIS modeling to determine the most suitable location for microalgae cultivation offer some insight as to the best location to base our design model on. The largest areas identified as capable of algae biofuel production exist along the coast from the south west of Karratha to the north west of Port Hedland. See Figure 6 This region provides ideal climatic conditions and suitable land in terms of limited topography relief and competing land use [15] (Bortowitza M., Boruff B., Moheinani N., Pauli N., Cao Y. \& Smith H. 2012).

Infrastructure and transport for this region are well developed with Port Headland set to expand its port offering good potential for the transport to process plants or the export of microalgae biofuel. Port of Port Headland is set to

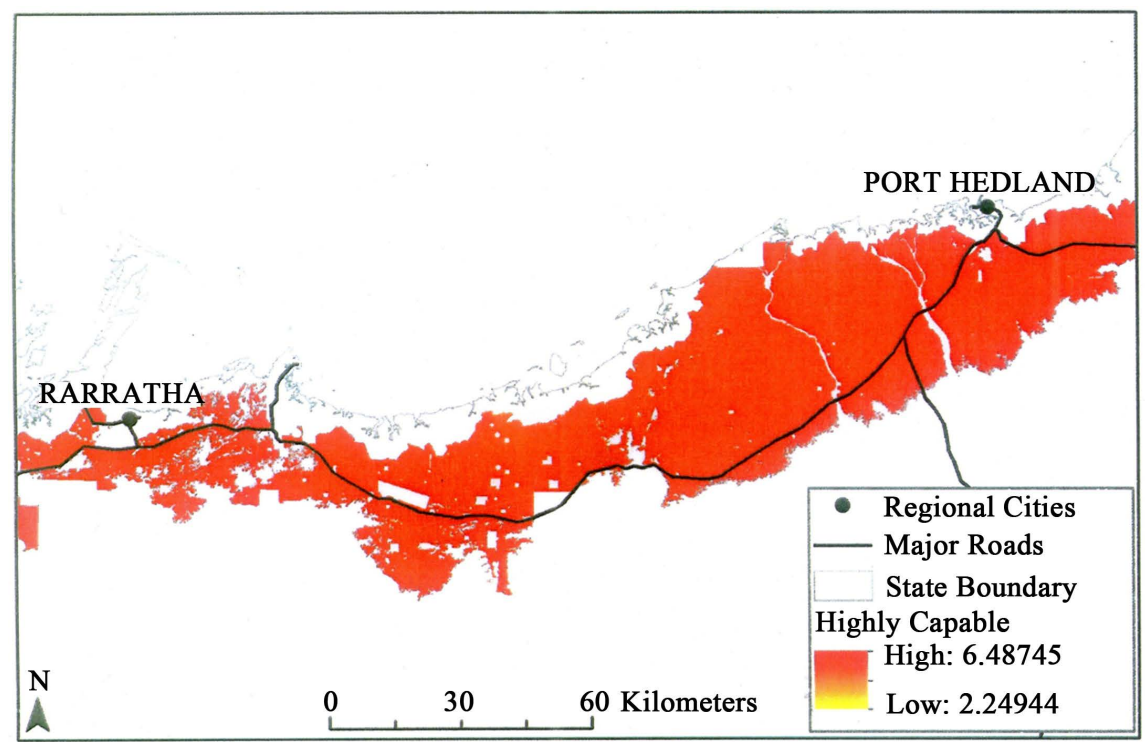

Figure 6. Example of GIS study for algae biofuel production potential. Source: (Abodeely J, Stevens D, Ray A, Schaller K \& Newby D 2013). 
increase its berth capacity from 9 to 21 within the inner harbor with a further 20 berths planned as part of the outer harbor [22] (Western Australian Planning commission 2009).

\section{Chosen Location in Pilbara Region near Port Hedland}

Port Hedland has manmade salt lake about $10 \mathrm{~km}$ to the east of the city known as Cargil Salt Farm which is operated by Dampier's salt as a salt product plant. A small natural salt lake connecting to the sea by Beedingarra creek exist a further $5 \mathrm{~km}$ to the east with an area of $6 \mathrm{sq} \cdot \mathrm{km}$ it has a water channel connecting to a larger salt lake/backwash around $20 \mathrm{~km}$ further east. The larger salt lake/backwash about $35 \mathrm{~km}$ east of the city have an area of approx $70 \mathrm{sq} \mathrm{km}$ with tidal estuaries adjoining the sea offering a reliable water supply and suitable topography.

A suitable potential location has been selected at the coordinates of -20.07141 , 119.07394 about $5 \mathrm{mtr}$ above sea level offering close proximity to the city, easy access and a reliable water supply. The location is crown land which is usually available for lease subject to many regulations and conditions. See Figure 7.

\section{Construction of Microalgae Biomass Plant in the Pilbara Region}

\subsection{Soil and Topography of Construction Site}

The site is reasonable flat, naturally well drained, with low growing vegetation and is made up of mostly sand with the presence of some stones to small rocks. Most of the coastal belt is alluvial plains of sand (Western Australian Planning Commission 2009) The soil type is a determining factor in the construction method of ponds particularly in regards to permeability. Sites that have sandy or gravel composition will either need clay brought in to seal the bottom of the

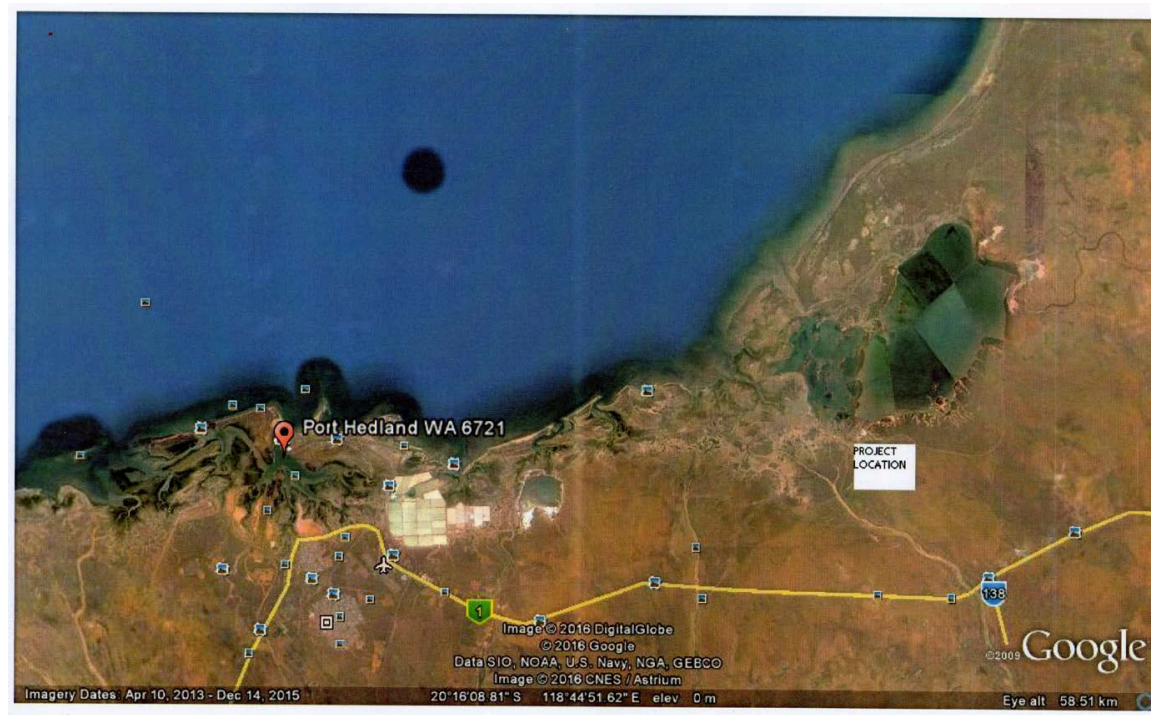

Figure 7. Ariel view of proposed location. Source: Google Earth. 
pond or a synthetic liner, both of which would incur additional cost [10] (Abodeely J., Stevens D., Ray A. Schaller K. \& Newby D. 2013). Geological soil testing would need to carried out before any construction was to commence.

\subsection{Open Raceway Pond Construction}

\section{Pond Structure}

The first step in constructing a microalgae raceway open pond is the pond itself and the liner to be used which can be the most expensive part of the project. Open ponds for algae production are relatively (compared to PBRs) simple in construction and operation [11] (Lundquist T., Woertz I., Quinn N. \& Benemann J. 2010). The cost of building such a pond depends on many factors such as size, terrain, soil base and access. The area terrain around Port Hedland is very flat with a sound rock and sand base offering good construction conditions and also an easy road surfacing base if required. Large scale algae production systems will require a certain amount of earthwork to meet the needs of the raceway design criteria and configuration [10] (Abodeely J., Stevens D., Ray A., Schaller K. \& Newby D. 2013). Before any construction can commence it is critical that the size ponds be established and a number chosen with the opportunity of further expansion at a later date with increase pond numbers. The size of the pond is determined by many factors such as land availability, construction restraints, and economics. To approach maximal economics of scale, individual growth ponds should be about 4 hectares in area [11] (Lundquist T., Woertz I., Quinn N. \& Benemann J. 2010).

See below the proposed specification for a pond in a project like this one. See Table 3 \& Figure 8.

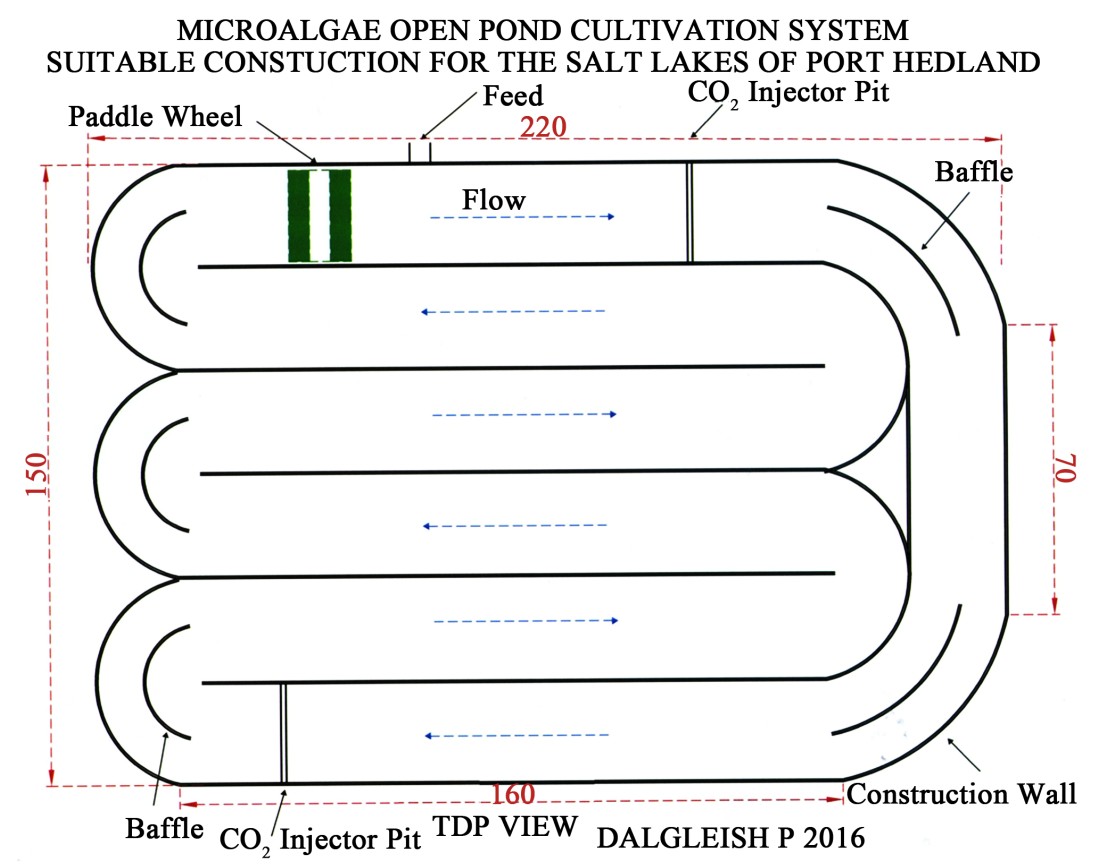

Figure 8. Microalgae open pond cultivation system. 
Table 3. Specifications of pond construction.

\begin{tabular}{cc}
\hline Material & Reinforced Concrete 20MPA \\
\hline Overall Dimensions & L 220 mtr W150 mtr D 1.0 mtr \\
Wall Thickness & $200 \mathrm{~mm}$ \\
Volume & $186,000 \mathrm{~m}^{3}$ \\
Area & $310,000 \mathrm{~m}^{2}$ or 3.1 Hectare \\
Water Depth & $0.6 \mathrm{mtr}$ \\
\hline
\end{tabular}

The depth of the pond is usually shallow such that it encourages so that light can infiltrate through to the full depth of the pond to simulate natural conditions. In this system, the shallow ponds usually about $1 \mathrm{ft}$ deep are used to culture the algae by maintaining conditions identical to their natural environment [7] (Gorden R. \& Seckbach J. 2012).

\subsection{Open Raceway Pumping System}

The transfer of water from the salt lake to the open pond can only be achieved from a pumping system with pumping also required for smaller applications such as to input of nutrients or water level control. All of these applications need to be carefully monitored by computer system that control all pumping and axillaries. The central processing facility will be equipped with the programming units that control the water/wastewater flow into and out of the pond while also automatically monitoring and controlling nutrient delivery [10] (Abodeely J., Stevens D., Ray A., Schaller K. \& Newby D. 2013). In transferring water from the supply to the pond, the pumping system must take into account factors such as the required suction, flow, pressure, to achieve the required results whilst also taking into account economics and energy requirements. Pump performance is measured in terms of the flow rate that the pump can discharge against a given head at a given efficiency [23] (Jones G. \& Sanks R. 2009). The pumping system needs to be able to replenish the water supply after occurrences such as natural evaporation and operational losses such as those that take place during harvesting. A water supply is necessary to make up for water lost through evaporation and blowout [11] (Lundquist T., Woertz I., Quinn N. \& Benemann J. 2010).

The Pilbara region is generally considered to be of a dry and hot region resulting in high evaporation rates which need to be carefully considered when designing an open pond raceway pumping system. It is noted that the Pilbara region contains some of Australia's consistently hottest places with highly irregular rainfall, where average yearly evaporation (approximately $3000 \mathrm{~mm}$ ) exceeds average yearly rainfall [36] (Regional Development Australia Pilbara Committee 2013). Evaporation losses in open pond raceway systems can be higher than reservoirs as a result of their structural type and continuous movement. However algae ponds are not reservoirs, being much shallower and mechanically mixed, and thus are expected to have high evaporation rates [11] (Lundquist T., Woertz I., Quinn N. \& Benemann J. 2010). 


\section{Pumping Requirements Calculations}

Evaporation Rate of 3000 per year $=8 \mathrm{~mm}$ per day

Double rate for peak days $+20 \%$ allowance for pond system $=20 \mathrm{~mm}$ per day approx

Losses $20 \mathrm{~mm} \times 3100 \mathrm{~m}^{2}$ area $=62 \mathrm{~m}^{3}$ (62,000 litre's) per day

or 2600 litre's per hour approx

The estimated required pressure is $30 \mathrm{mtr}$ head

The pumping system delivery a minimum of 2600 litre's per hour @ 30 $\mathrm{mtr}(300 \mathrm{kpa})$

See Figure 9.

The function of the pumping system needs to be as energy efficient as possible which is best achieved by utilizing several pumps in parallel. Another efficient method of flow control, particularly for systems where static head is a high proportion of the total, is to install two or more pumps to operate in parallel [37] (Europe pump and Hydraulic Industry 2004). These pumps can come on individually as demand increase or decreases to ensure only the immediate required workload is allowed for by running only the combination of required pumps. Pumps in parallel are often used when the system has variable flow requirements and when these requirements are met by switching the parallel-connected pumps on and off [23] (Grundfos Handbook 2004).

The pumping system incorporates a filtration system as part of the assembly. See details under Filtration Systems
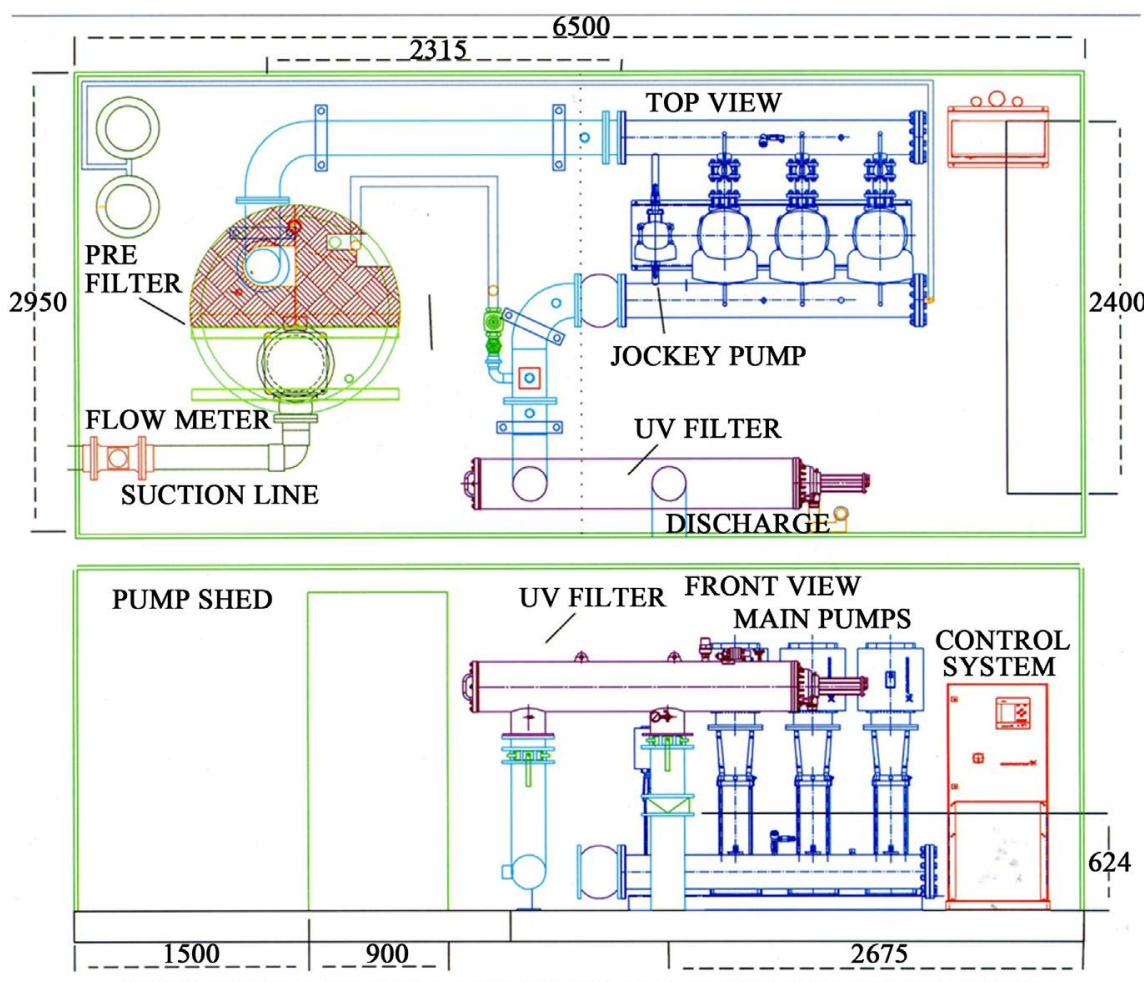

PROPROSED PORT HEDLAND MICROALGAE CULTIVATION PUMP SET DALGLEISH P 2016

Figure 9. Typical pump \& computer control system. 
The chosen pumping system shall incorporate $3 \times$ CR 10-4 Main Pumps and $1 \times$ CR 5-4 Jockey Pump

Jockey pumps have the function are common place in pumping systems to assist in energy efficiency. They have the function of coming into operation when only a small demand (less than a main pump) is required or operating when the demand requires a small boost from the currently operating pump/pumps. Jockey Pump: A small pump that maintains pressure in a piping system during periods of low demand [23] (Jones G. \& Sanks R. 2009).

Pump Specifications for Grundfos CR 10-4 (See Figure 10).

When all the pumps are configured in parallel the pressure remains the same but each pump contributes to the flow making it easy to achieve the maximum required flow while still having the option of delivering small flows at constant pressure. As shown in Figure 11.

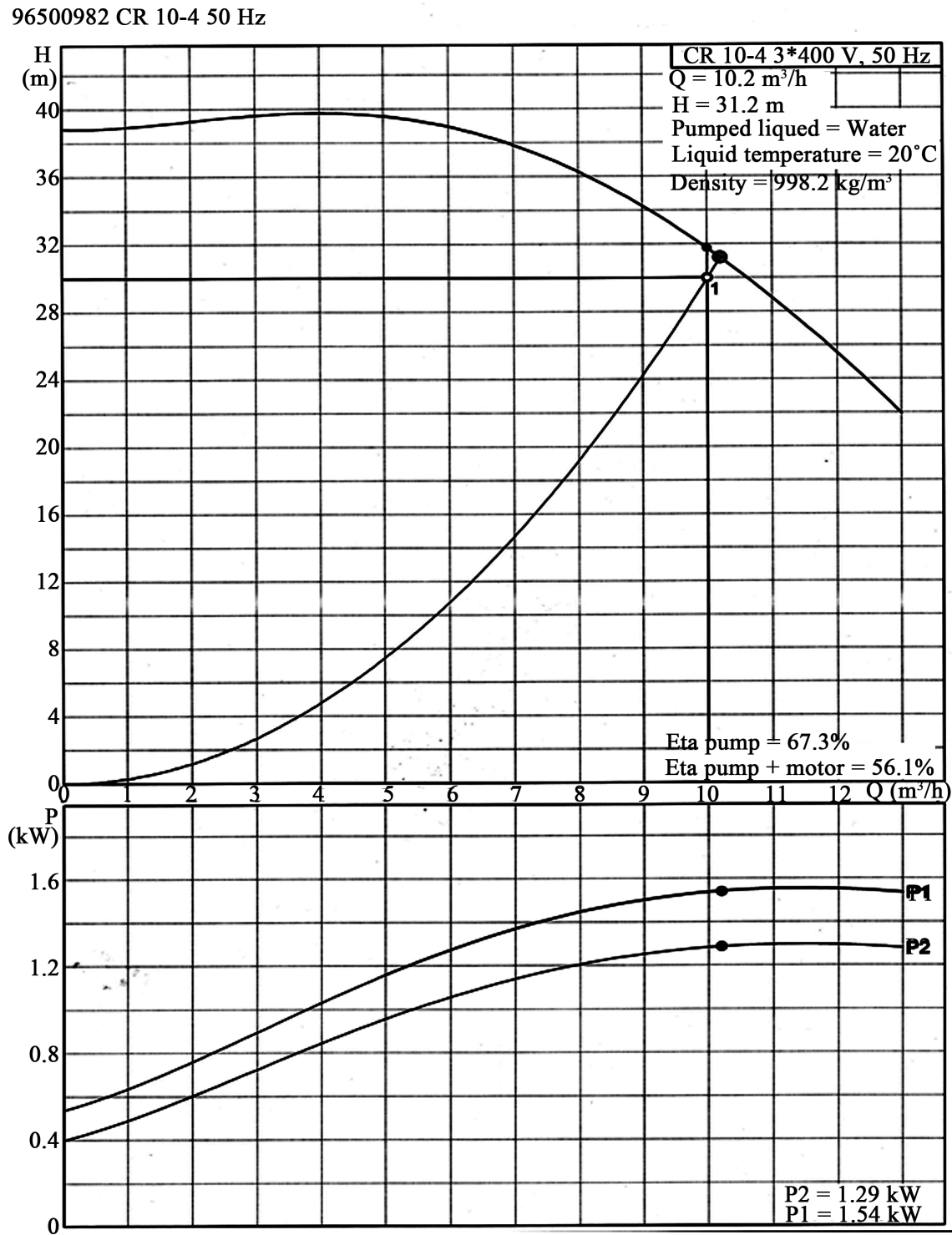

Figure 10. Source: Grundfos pumps. 


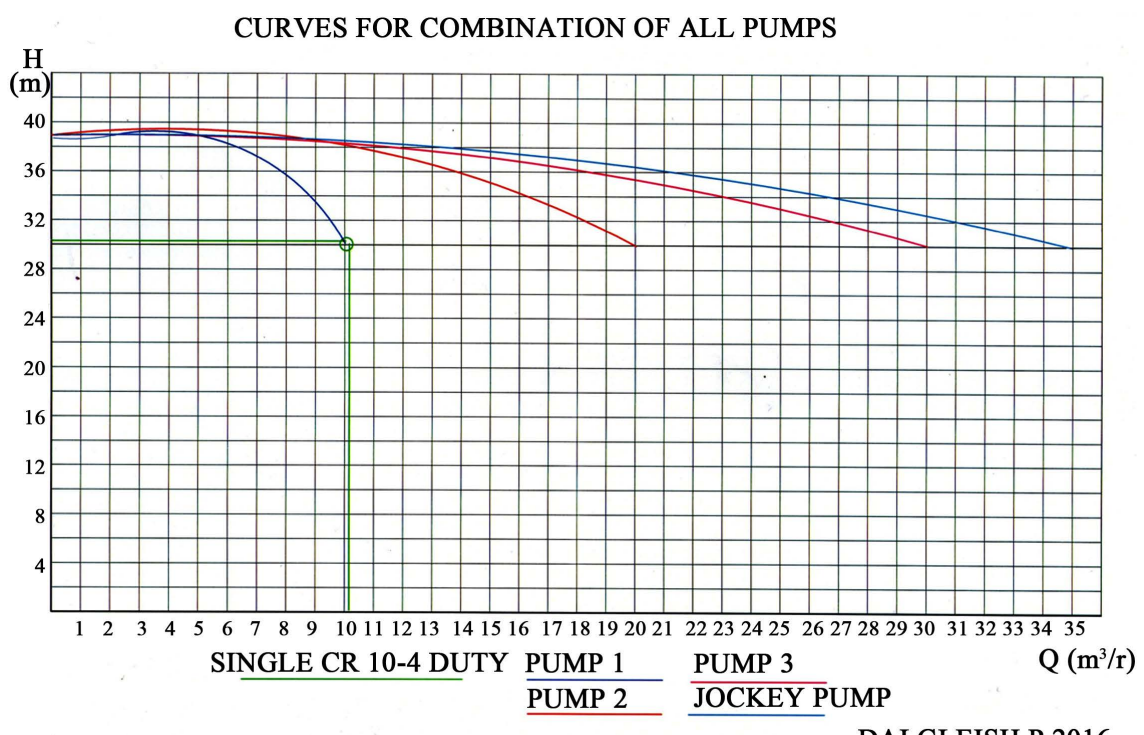

Figure 11. Curves for combination of all pumps.

A pump suction line from the water source to the pumping system must be constructed with strong focus on the vertical suction height which should never exceed $6 \mathrm{mtr}$ 's from the lowest annual water level. The pump would not be more

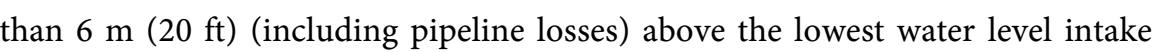
[23] (Jones G. \& Sanks R. 2009). The suction line should continuously rise from the water source to the pump intake to avoid air locks. Air Pockets created when a portion of the suction pipe has a negative slope can be avoided with careful layout and installation of the suction line [24] (Yedidiah S. 1996). A foot valve must be installed at the start of the suction line under water level to ensure that the pump is constantly primed. The force exerted by preloading should be great enough to shut the foot valve before the returning liquid has acquired a significant velocity [24] (Yedidiah S. 1996).

Pump Energy Consumption: Main Pumps CR 10-4 1.5 kW Jockey Pump CR5-6 $1.1 \mathrm{~kW}$

Total Energy Consumption: $3 \times 1.5 \mathrm{~kW}+1 \times 1.1 \mathrm{~kW}=6.6 \mathrm{~kW}$

Total per Day: $6.6 \mathrm{~kW} \times 4$ hours per day $=26.4 \mathrm{kWh}$ per Day

\subsection{Filtration Systems}

Water supply filtration is critical in the operation of microalgae cultivation systems for the removal of many foreign organic and inorganic particles and organisms. Filtration as a fluid-particle separation process is an engineering practice of long standing [30] (Tien C. 2012).

The pump station has 2 levels of filtration including a pre-filter that must be installed upstream of the pumps to ensure that larger foreign materials do not enter the pump resulting in pump damage. If an impeller becomes clogged or damaged the pump must be pulled to the motor room floor for servicing [23] (Jones G. \& Sanks R. 2009). The second system of filtration within the pump sta- 
tion is an ultraviolet system designed to kill any living organism's (including other microalgae species) present in the water supply that may contaminate or compete with the desired crop. One of the main obstacles for continuous productivity in microalgae cultivation is the presence of biological contaminants capable of eliminating large numbers of cells in a matter of days or even hours [24] (Brantes L., Mendes B. \& Vermelho A. 2013).

The pre-filter must be fine enough to remove any particles from the water that may be damaging to the pumping system but not so fine that blockages are take place quickly or too much friction loss occurs due to difficult passage. In the long term filters or strainers become clogged: this is their purpose [34] (Bachus L. \& Custodio A. 2006). Careful calculations must be done to ensure that the filter self flushes before friction losses due to clogging have a detrimental effect on the pump. What must be done is establish the maximum flow, and the minimum flow, and implement controls [34] (Bachusl \& Custodio A. 2006).

The ultra violet system must be efficient enough to minimize the risk that any other competing species is able to enter the system via the water re-fill process. The open pond system has a series disadvantage of being susceptible to contamination by unwanted species if utmost care is not taken [2] (Singh N. \& Dhar D. 2010). Ultra violet light system have the advantage of killing incoming algae as they pass through the filter but not affecting the cultivated microalgae downstream of the filter. Both Ozone and ultra violet light, as well as being a effective disinfecting agent, leave no toxic residual [15] (Bortowitza M., Boruff B., Moheinani N., Pauli N., Cao Y. \& Smith H. 2012). The open pond system should also providing ideal conditions for the selected species cultivated. For long term culture stability and minimal contamination problems it is essential that the culture conditions are optimized for the species being grown so that they can out compete any contaminating species [15] (Bortowitza M., Boruff B., Moheinani N., Pauli N., Cao Y. \& Smith H. 2012).

The Selected UV Filter for this application Steriflo Model ALX 4/6: See pictured in Pump Set

Filter Power Consumption 815 Watts $\times 4$ hrs per day.

Total energy Consumption $3.3 \mathrm{kWh}$ per day

\subsection{Paddle Wheel System}

The paddle wheel systems main application is to start and maintain the flow of water through the raceway whilst mixing all nutrients etc. Pond mixing can be accomplished by current state of technology paddle wheels designed for raceway ponds [10] (Abodeely J., Stevens D., Ray A., Schaller K. \& Newby D. 2013). The correct size of wheels and paddles is determined by the size of the pond and for large ponds the design usually allows for the water movement to be $20-30 \mathrm{~cm}$ per second. Considerations for the number of paddle wheels for each pond are calculated on the dimensions of the channels. The design of the paddle wheel usually includes 8 blades per wheel to try to minimize power use by creating constant force resulting in even power usage. If one of the blades are not always 
immersed then there is no increased power requirement when the blade first enters the water due to sudden resistance encountered by the blade as it enters the water [3] (Borowitzka Moheimani 2012). The power usage of paddle blades can be considerable meaning correct design is critical. See Figure 12.

Paddle Wheel Energy Consumption: $37 \mathrm{~kW} \times 24 \mathrm{hrs:}$

Total Consumption $888 \mathrm{kWh}$ per day

\subsection{Control System}

The control and monitoring system is usually incorporated within the pumps computer system and is responsible for monitoring and adjustment of many cultural environments such as temperature, $\mathrm{PH}$, salinity, carbonation and nutrients. This system is made up of many different types of sensor that are located throughout many parts of the raceway to ensure precise readings of environmental conditions so that suitable adjustments can be automatically made. The central processing facility will be equipped with programming units that control water/wastewater flow in and out of the pond while also automatically monitoring and controlling nutrient delivery [10] (Abodeely J., Stevens D., Ray A., Schaller K. \& Newby D. 2013). These systems, however reliable are still subject to error and from time to time these parameters should be monitored manually whilst also watching the algae health to ensure a viable crop. Ideally, the plant manager and operations supervisor will monitor pond conditions and identify culture conditions where specific samples need to be collected for analysis [10] (Abodeely J., Stevens D., Ray A., Schaller K. \& Newby D. 2013).

The Daily Power Consumption of the Control System and Sensors is Minor

Estimated Power Consumption $12 \mathrm{kWh}$ per day

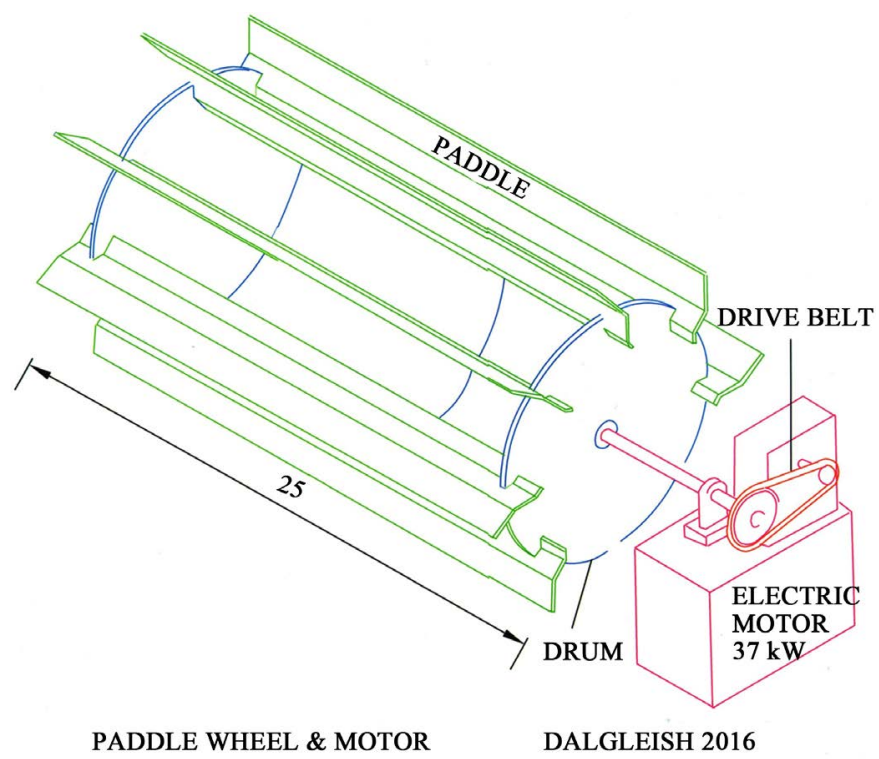

Figure 12. The daily power consumption of the control system and sensorsis minor estimated power consumption $12 \mathrm{kwh}$ per day. 


\subsection{Carbonation System}

Carbonation Pumps are designed to add carbon dioxide to the water which enhances the growth of algae. Most algae cultures are carbon limited and the addition of a carbon source such as carbon dioxide will enhance productivity [3] (Borowitzka Moheimani 2012). During peak growing times such as summer carbonation levels need to be higher to accommodate for faster intakes due to rapid growth. Wastewater can have the advantage of high in organic carbon organic levels assisting in the further enhancement of growth. Organic carbon from wastewater is another form of carbon used for algae cultivation [10] (Abodeely J., Stevens D., Ray A., Schaller K. \& Newby D. 2013). Sourcing carbon from wastewater also offers environmental advantages as well as being a good carbon source. The $\mathrm{CO}_{2}$ supplied to algal cultures helps to maximize algal growth and simultaneously reduce the environmental pollutants [7] (Gorden R. \& Seckbach J. 2012). Carbon pumps are usually placed located at several points throughout the raceway pond to ensure even distribution of carbon. The units are located roughly 1-m deep and have a concrete pad or inlaid cinder blocks to decrease the amount of erosion of moving culture [10] (Abodeely J., Stevens D., Ray A., Schaller K. \& Newby D. 2013). The amount of carbon injection should be adjusted to take into account the seasons and growth periods. During peak operation during the summer months the need for equivalent carbon is greater due to greater productivities [10] (Abodeely J., Stevens D., Ray A., Schaller K. \& Newby D. 2013).

The design of the carbonation system should take in account the size of the pond, number of carbonate systems and energy use. Pond size and/or the number of carbonation stations is determined by the carbon storage capacity of the water [26] (Weissman J. \& Goebel R. 1987). Carbonate systems require more depth than the growing conditions to operate efficiently so sumps must be constructed (1.2 to $1.5 \mathrm{mtr}$ ) to allow for this. Sumps are necessary in order to provide a deepened area for $\mathrm{CO}_{2}$ additions so that high absorbtion is achieved, and to provide a collection point for draining the pond [26] (Weissman J. \& Goebel R. 1987). The bubble release system needs to be designed to maximize the delivery of $\mathrm{CO}_{2}$ into the water. The gas transfer efficiency can be improved by using smaller bubbles through the use of sintered porous stones or pipes, resulting in larger gas-liquid interface area compared to larger bubbles [3] (Borowitzka Moheimani 2012). As shown in Figure 13.

Continuing research is underway to determine the optimum $\mathrm{CO}_{2}$ to water ratio for efficient algae growth. However, initial values for values for saturation region sharply vary from author to author-from $0.1 \%$ to $10 \%$ [27] (Gitelson J. \& Lisovsky G. 2003). The pump size and number of pits for a open raceway pond is very dependent on many factors and should also take into account energy consumption. The device supplying the $\mathrm{CO}_{2}$ optimizes the purification of the gas used as sources of $\mathrm{CO}_{2}$, adjusting its flow and design system to achieve high gas purification and therefore, a greater utilization of the $\mathrm{CO}_{2}$ supplied, with minimum energy consumption [28] (Patent EP2712917 A1 2013). 


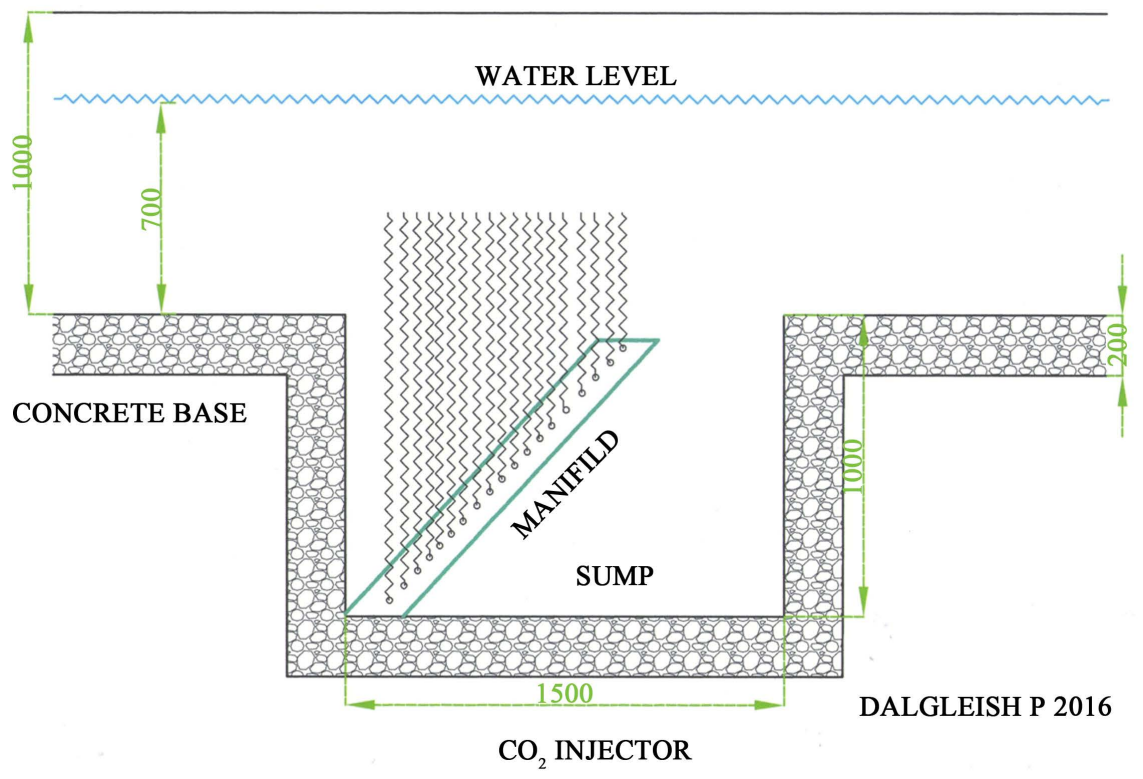

Figure 13. $\mathrm{CO}_{2}$ injector pump motor energy consumption $5.8 \mathrm{~kW} \times 12 \mathrm{hrs}$. Total consumption $139 \mathrm{kWh}$ per day.

In this application $2 \times$ Injector Sumps shall be included operating from one pump

\section{Harvesting of Microalgae Biomass Plant in the Pilbara Region}

The harvesting of microalgae can be an expensive part of the algae biomass production. Harvesting cost may contribute $20 \%-30 \%$ to the total cost of algae biomass [1] (Demibras A. \& M. 2010). Determining the most suitable harvesting system requires consideration of many different conditions. The harvesting method depends on the species, on the cell density, and often also the cultural conditions [1] (Demibras A. \& M. 2010). The most suitable harvesting system should also take into considering the energy use and availability for the particular conditions. Algae can be harvested by centrifugation, flocculation or froth floatation [1] (Demibras A. \& M. 2010).

Flocculation is a chemical process relying on the interaction of negatively charged particles resulting in larger particles that can be collected much more easily. Flocculation involves the aggregation of destabilized particles and the precipitation products formed by one or more coagulants into larger particles known as flocculant particles or, more commonly, "flocs" [3] (Borowitzka M. Moheimani N. 2012). This process may also assist in the dewatering stage of algae biomass production.

Centrifugation is an effective way of harvesting algae but can result in high energy use due to the need to use electrically operated mechanical devises known as decanters. Centrifugal processes rely on the generation of a centrifugal force which acts radially and accelerates the movement and separation of particles 
based on density difference between the particle and the surrounding medium [3] (Borowitzka M. Moheimani N. 2012).

Froth Flotation is often used in waste water treatment as a separation method of unwanted contaminates, but now offers a method for removing desired algae particles. Flotation is a separation process based on air or gas bubbles adhering to the particles, which are then carried to the liquid surface where they can be separated, usually skimming [3] (Borowitzka M. Moheimani N. 2012). This process also requires the use of electrical aerators which can be energy use extensive.

Many other forms of algae harvesting have been trialed with some success, some of which are used in combination with flocculation, centrifugation or froth flotation. In this case a combination of flocculation and centrifugation shall be proposed as the most reliable method of harvesting. The harvesting elements often used in large-scale production first include natural settling of the culture followed by a primary harvesting step using flocculation while secondary harvesting uses a centrifuge [10] (Abodeely J., Stevens D., Ray A., Schaller K. \& Newby D. 2013).

\subsection{The Flocculation Process}

Chemical flocculation is a method of reducing harvesting cost by minimizing the energy required in the centrifugation process due to the flocs being more dense and responding more readily to centrifugal forces. The resultant flocs are generally easier to recover by the traditional solid -liquid separation techniques [3] (Borowitzka M. Moheimani N. 2012). Different species of algae react differently to the chemicals used for flocculation requiring the some alterations in chemical types and ratios. All algae strains do not respond the same to a particular chemical, so tailoring will be required to fit the organism being harvested [28] (Moheimani H., McHenry M., de Boer K. \& Bahri P. 2015). Care must be taken when choosing chemical for flocculation as negative effects may occur as a result of remaining residue. Negative impacts have been countered in a number of ways, including the use of degradable biopolymers as flocculants (e.g. polyarcylamide and starches) and electroflocculation where no flocculant is directly added [28]. (Moheimani H., McHenry M., de Boer K. \& Bahri P. 2015). Inorganic and organic flocculants have been trialed in the microalgae harvesting process with indications that organic flocculants have less negative effects. It is reported that these biodegradable polymers do not contaminate the biomass as much as inorganic coagulants and that cationic polymers are superior to anionic and neutral ones [28] (Moheimani H., McHenry M., de Boer K. \& Bahri P. 2015).

\subsection{The Centrifugation Process}

Centrifugation combined with some flocculation is currently the most common and reliable form of microalgae harvesting but requires a lot of energy and expensive equipment. It is flexible and can run continuously to handle huge vo- 
lumes to scale [28] (Moheimani H., McHenry M., de Boer K. \& Bahri P. 2015). Decanter type centrifugation devices are proving to be efficient and effective. The decanter or scroll centrifuge is one of the most promising centrifugal devices for the recovery of microalgae as they can operate continuously, have high capacity and lower maintenance requirements [3] (Borowitzka M. Moheimani N. 2012). Their construction is usually two concentric rotating blades surrounded by a stationary casing. Solids enter the decanter settle on the bowl wall to be discharge, while the clarified liquid is discharged at the other end [3] (Borowitzka M. Moheimani N. 2012).

The centrifugation process has presented itself as a very reliable and effective method of microalgae harvesting but the capital cost can be high and the energy consumption level is considerable. Although centrifugation is a proven technology for the fast and effective means of harvesting most microalgae, its use and the high capital and operational cost, must be considered in conjunction with the scale and value of the product. (Borowitzka M Moheimani N 2012)

Decanter type centrifugation has the benefit of removing a lot of the water during the algae harvesting process reducing the dewater requirements. The dewatered biomass using the decanter centrifuge is much more concentrated than that achieved using the disc centrifuge [29] (Al hattan M., Ghaly A. \& Hammouda 2015). See Figure 14.

\section{Decanter Motor Energy Consumption $8.0 \mathrm{~kW} \times 24 \mathrm{hrs}$ \\ Total Consumption $160 \mathrm{kWh}$ per day}

\subsection{The Dewatering Process}

Dewatering is partly achieved through the centrifugal equipment process. In general, centrifugation is an energy intensive process and has been suggested as secondary dewatering process to reduce cost. Sun drying is low cost method of dewatering requiring space but little equipment other than sunlight which is in abundance in the Iran Salt Lakes regions. Sun drying can be an economically viable option for drying algae biomass without additional fuel consumption [10] (Abodeely J., Stevens D., Ray A., Schaller K. \& Newby D. 2013). The only equipment required for this process is drying mats and some form of machinery to transfer the microalgae.

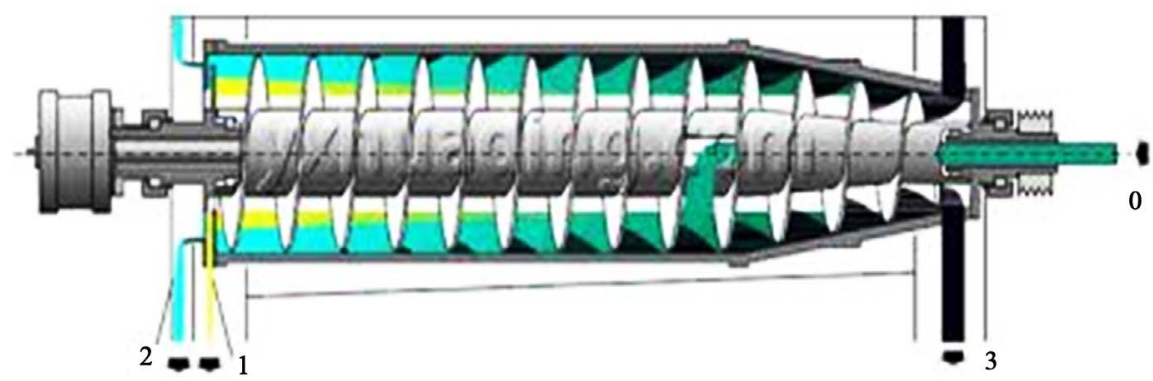

Figure 14. Typical decanter type device. The estimated energy usage for a decanter centrifugation system is $\left(8 \mathrm{kWhm}^{3}\right)$ water. Source: [3] (Borowitzka M. Moheimani N 2012). 


\section{Construction \& Operational Cost for the Microalgae Biomass Plant}

\subsection{Construction Cost}

The construction of a project such as this is very difficult to cost and therefore this paper shall attempt to produce a budgetary price only with further research required to produce an accurate construction price. See Table 4.

The construction price shall be affected by many variables such as:

- Local labor costs

- The cost of materials and transport

- Any government grants or private investment

- Availability of local machinery or equipment Efficiency of time restraints of construction

\subsection{Operational Costing}

The operational costs are easier to predict than due to ease of regular and predictable chemical, power and labor prices. See Table 5 Costs are generally high compared to other agricultural enterprises due to the need of vast amounts of chemical and power requirements. Producing microalgae biomass is generally more expensive than growing crops [1] (Demibras A. \& F. 2010).

Table 4. Source: [1] (Demibras A. \& F. 2010) allowing for location, time and system type.

\begin{tabular}{|c|c|}
\hline Capital Works & Cost Per Hectare \\
\hline Earth Works & $\$ 20,135.00$ \\
\hline Primary Ponds Wall \& Structure & $\$ 16,604.00$ \\
\hline Carbonation System & $\$ 5986.00$ \\
\hline Instrumentation & $\$ 1000.00$ \\
\hline Water Supply Distribution & $\$ 8852.00$ \\
\hline $\mathrm{CO}_{2}$ Distribution & $\$ 842.00$ \\
\hline Nutrient Distribution & $\$ 1562.00$ \\
\hline Flocculation Equipment & $\$ 12,934.00$ \\
\hline Settling Pond & $\$ 14,958.00$ \\
\hline Buildings & $\$ 3438.00$ \\
\hline Electrical Distribution Supply & $\$ 8330.00$ \\
\hline Machinery & $\$ 2502.00$ \\
\hline Pump Station & $\$ 3500.00$ \\
\hline Land Acquisition & $\$ 36,500.00$ \\
\hline Drying Mats & $\$ 2700.00$ \\
\hline Construction Labor, Project Management \& Consulting Cost (35\%) & $\$ 111,566.00$ \\
\hline Total per Hectare & $\$ 251,409.00$ \\
\hline Total for 3.1 Hectare & $\$ 779,367.90$ \\
\hline
\end{tabular}


Table 5. Source: [1] (Demibras A. \& M. 2010) allowing for made for location, time and system type.

\begin{tabular}{cc}
\hline Operational Cost per Year & Cost Per Hectare \\
\hline $\mathrm{CO}_{2}(2 \mathrm{~kg} / 2 \mathrm{~kg}$ biomass $)$ & $\$ 12,580.00$ \\
Superphosphates & $\$ 1070.00$ \\
Flocculants & $\$ 5500.00$ \\
Power Mixing (97.236 kWH per hectare) & $\$ 19,447.00$ \\
Harvest (15,730 kWH per hectare) & $\$ 3146.00$ \\
Pumping \& $\mathrm{CO}_{2}$ Injection $(18,111 \mathrm{kWH}$ per hectare $)$ & $\$ 3622.00$ \\
Power Production (6.5 c/kWH) Solar, Wind etc & $(\$ 7564.00)$ \\
Salt Disposal (\$200/mt) & $\$ 3390.00$ \\
Maintenance & $\$ 5880.00$ \\
Labor & $\$ 21,000.00$ \\
Total Operational per Hectare, Year & $\$ 75,635.00$ \\
Total for 3.1 Hectare, Year & $\$ 265,468.00$ \\
\hline
\end{tabular}

\section{Economic Viability}

\subsection{Expected Yield}

The expected yield of oil from microalgae per hectare is paramount in determining the viability of a project of this type. The oil level of microalgae from the Salt Lakes of the Pilbara is expected to be high due to the excellent natural conditions of the site. The paper considers Pilbara salt lakes as natural reactors for biofuel production. See Table 6.

\subsection{Cost of Biofuel per Litre}

The Construction Cost will be depreciated at a rate 25 year

Construction Cost per hectare $\$ 251,409.00 / 25$ years $=\$ 10,056.00$ per year

Operational Cost $=\$ 75,635.00$ per year

Total Production Cost $=\$ \mathbf{8 5 , 6 9 1 . 0 0}$ per year per hectare

Expected Yield $=\$ 95,000$ Liter Year $/$ hectare

Production Cost $=\$ 0.90$ per liter

The cost of 0.90 cents per liter sounds like a viable fuel supply and in most countries this would be a cheap form of fuel if it was the price at the pump. However there is a lot more cost that need to be considered to get the figure in perspective.

- Transport from point of production to refinery

- Refinery cost

- Transport to point of sale

- Taxes

- Profit 
Table 6. Source: [31] (Goa Y., Gregor C., Liang Y., Tang D. \& Tweed C. 2009).

\begin{tabular}{cc}
\hline Expected Yield & Per Hectare, Year \\
\hline Microalgae (70\% oil by dry weight) Oil Yield & 95,000 Liter/Hectare \\
\hline
\end{tabular}

The actual cost of fossil oil production is currently around $\$ 12$ per barrel in the USA and \$10 per barrel in the Middle East with 159 liters per barrel [30] (Krisfopher G. 2015).

\section{$\$ 11 / 159$ litres $=6.9$ cents per litre}

This cost of fossil oil production is clearly much cheaper than microalgae, showing a changing depleted fossil fuel market and more efficient microalgae production is required before microalgae can compete with fossil oil from an economic point of view.

\subsection{Reduced Cost from Using Wastewater}

Wastewater from local industries or agriculture often contain contaminates that increase the yield of microalgae, whilst at the same time reducing the operational cost of cultivation. Thus, some wastewaters can be used as both carbon and nitrogen sources for cultivation of microalgae [28] (Moheimani H., McHenry M., de Boer K. \& Bahri P. 2015). The added advantage of using wastewater is the opportunity of the microalgae plant doubling as a water treatment plant returning water that may be suitable for re-use to its source. Cultivation of microalgae in wastewater for biodiesel production is highly desirable since it leads to a significant reduction in the production cost and reduction in the demand for freshwater with the con-cominitant removal of varies contaminants, such as phosphorus, nitrogen, heavy metals, and pathogens from the wastewater [28] (Moheimani H., McHenry M., de Boer K. \& Bahri P. 2015).

Further research of wastewater availability and treatment in the Port Headland region would be required to determine if a significant improvement in the efficiency and viability of the plant can be achieved. This research is beyond the scope of this paper and would need to be explored in future papers.

\subsection{Reduced Cost from Local Renewable Energy Production}

The Port Headland region is blessed with ample daily sunlight hours (average 11 hours per day) all year round making it an ideal candidate for the production of solar electricity and the opportunity of the microalgae being self sufficient in its power supply. As shown in Figure 15.

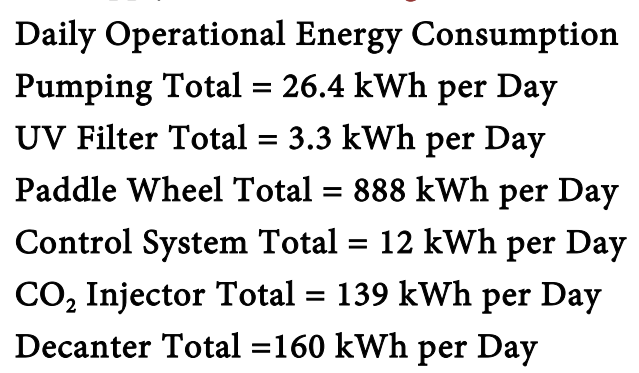




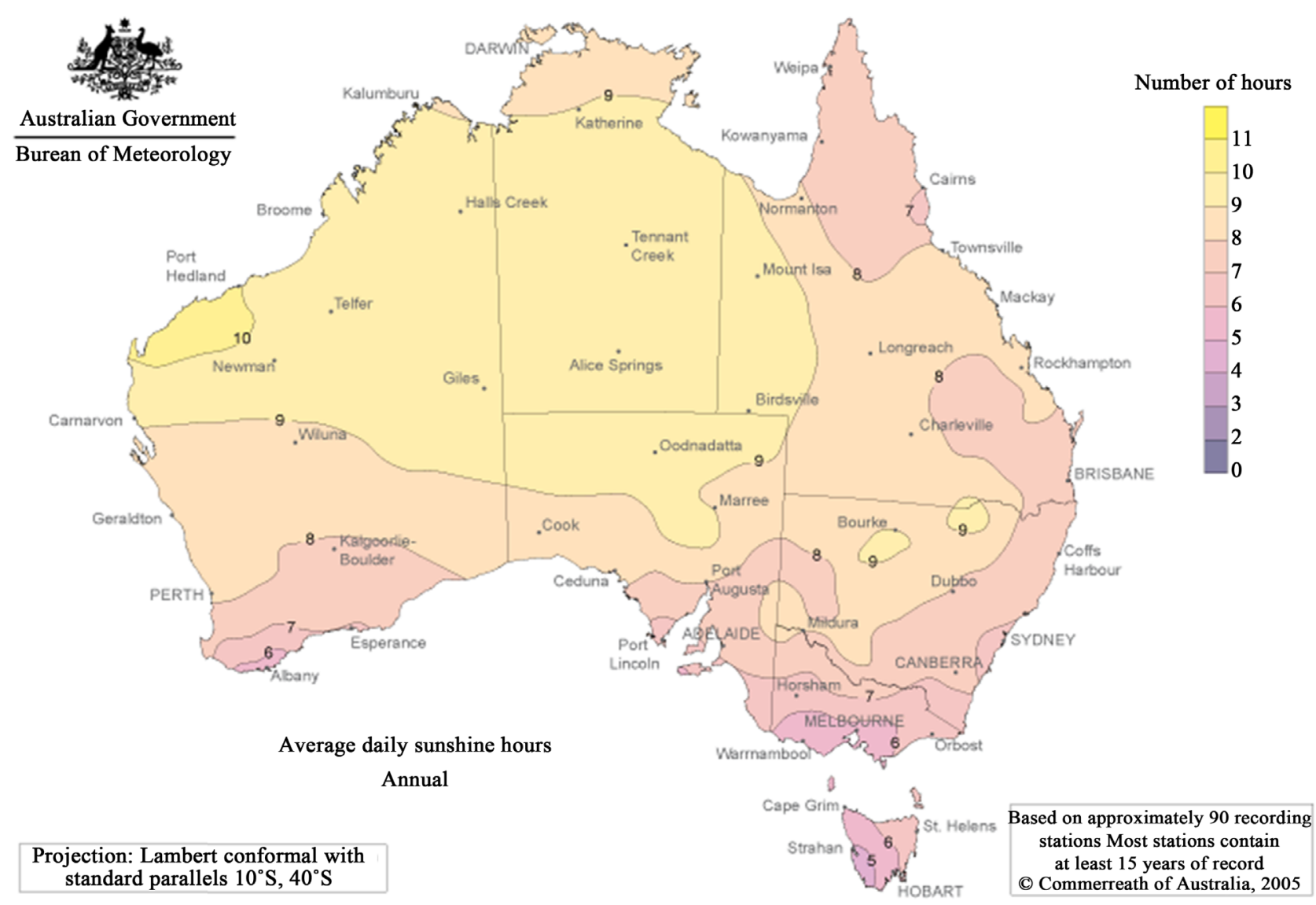

Figure 15. Map showing port Hedland's daily sunlight hours. Source bureau of meteorology.

Total of all Energy Consumption $=1229 \mathrm{kWh}$ per Day or $1.229 \mathrm{mWh}$ per day

Producing all the required energy by renewable sources on site has the potential to save $\$ 26,215.00$ per year from the overall operational cost per hectare.

This would bring the production cost down to 73.2 cents per liter

The most viable opportunity of producing renewable energy on site would appear to be solar due to Port Hedland having an average of 11 hours sunlight per over the entire year. Unfortunately this would result in further construction cost which would result in an increase in production cost.

The energy required to run the plant at $1229 \mathrm{kWh}$ per Day with 11 hours sunshine per day results in a $111.72 \mathrm{~kW}$ system required.

The average solar panel is rated at $260 \mathrm{~W}$

$111.72 \mathrm{~kW} / 260 \mathrm{~W}=430$ Panels would be required

The area required to house the solar panels to produce a required amount of power varies a lot depending on local conditions. With the existing levels of energy conversion efficiencies the land area for a solar power plant is fairly large about 2.5 - 3.0 hectares per megawatt (depending on technology) for solar PV technology, and about 2.5 hectares for CSP technology [32] (Asian Development Bank 2011). See Figure 16. 


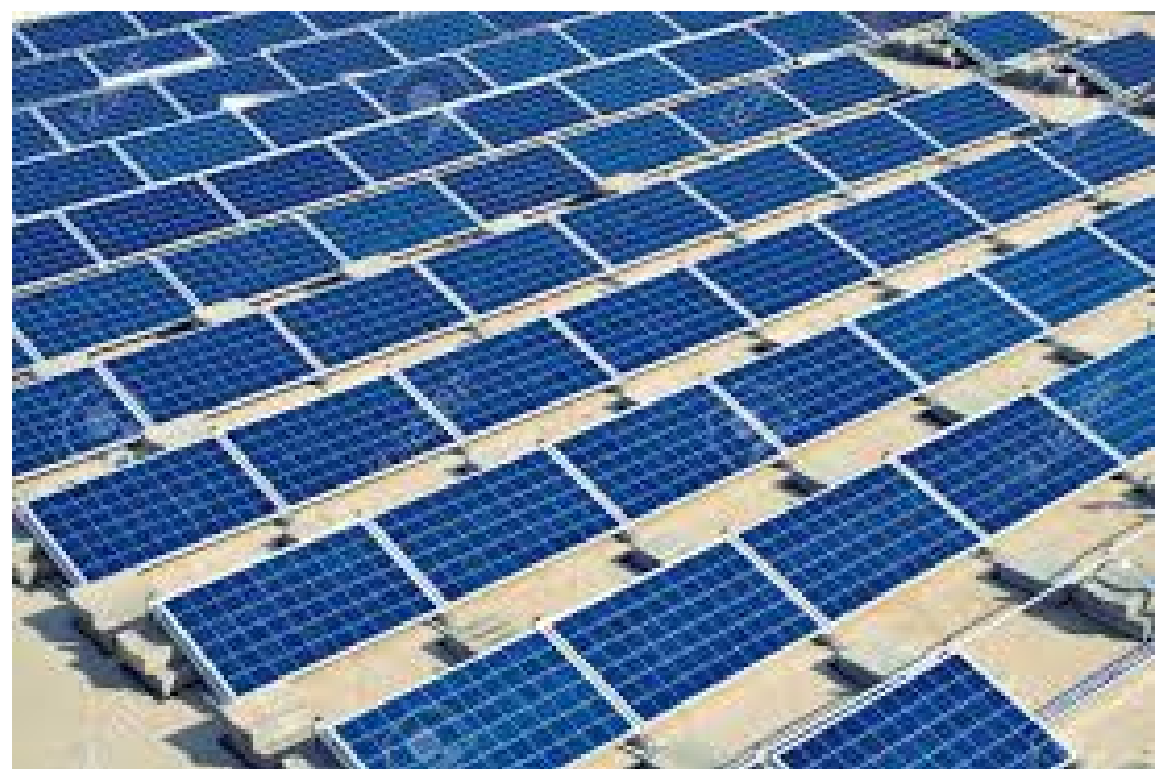

Figure 16. Typical open field solar array layout.

The required land area system for the system based on 1 MW per Hectare 2.5/0.111 $\mathrm{MW}=0.275$ of a Hectare

The area of 0.275 hectare is a small amount of land in comparison to the area of the raceway pond of 3.1 Hectare.

The overall cost of building a Solar Farm in Australia up to $1 \mathrm{MW}$ is estimated at \$2.51 per watt [33] (Source: Solar Farm Feasibility Study 2010).

$0.111 \mathrm{MW}$ or $111 \mathrm{KW} \times 2.51$ per Watt $=\$ 278,610.00$

$\$ 278,610.00$ depreciating over 25 years

$\$ 278,610.00 / 25=\$ 11,144$ per year

Construction Cost including Solar Plant $=\$ 21,200.00$ per year

Operational Cost including Solar Plant $=\$ 50,420.00$ per year

Total Cost $\$ 71,920.00$ per year

Expected Yield 95,000 Liter

This results in a new cost of 75.7 cents per liter

The above figures indicate that it is well worth utilizing the sunlight hours per day at Port Hedland. Not only does it make the production cost per liter of microalgae biofuel more viable but it also offers many environmental advantages.

The site may also offer potential for wind power production but the actual figures are beyond the scope of this paper.

\section{Conclusions}

The concept of growing microalgae as a form of renewable energy has been in practice for decades with some encouraging results and figures emerging. Until very recent years, when the price of fossil fuels was increasing at a rapid rate, it appeared that biofuel's (particularly microalgae biomass) were becoming competitive in the market place. But at the time that this paper was written there seems a worldwide fall in fossil fuels prices indicating that biomass fuels will not 
be able to compete in the near future. With world oil supplies depleting it is hard to visualize oil prices continuing to drop or even holding current prices. Many international political factors seem to be contributing to falling fossil fuel prices; however this could open the door to very quick changes and a reversal in pricing. Continuous economic growths in countries such as China and India must serve to increase the world demand for fossil fuels, and in fact all energy types. The number of vehicles, planes and other transport types are still growing worldwide with no sign of a leveling off or reduction in this activity. Recent technologies such as hybrid and electric cars are giving indicators of some trends away from fossil fuels but currently this is being out-stripped by increase vehicle numbers.

The problem of pollution and smog in cities due to transport is a constant reminder that some of the expectations of what we humans consider acceptable forms of transport must change. This united with growing awareness of climate change can only result in a long term move away from fossil fuels and the focus of alternatives such as biofuels. In a time such as now, when large political changes are occurring such as the Unites States elections and the Paris agreements it is hard to predict if positive or negative steps towards climate change are likely to occur in the near future. However the writer is confident in the long term that continued education and human awareness of the world's environmental problems will continue to be focused on and resolutions shall be sought.

Despite the efforts of trying to locate and develop the most viable microalgae conditions the numerical findings of this paper do not result in favorable indicators for growing microalgae as fossil fuels in the world's current economic climate. Fortunately the growing of microalgae offers itself to many other industries such as water treatment, the production of cosmetics and pharmaceutical products giving good reasons for continuing research. The prospect of utilizing microalgae for water treatment and producing other microalgae products during the same application has proven potential and this alone gives grounds for more research. Further research in species, locations and cultivation methods is likely to lead to greater yields and reduced operational cost with the opportunity of captivating markets in years to come.

With continued research and greater world awareness of environmental issues it is the view of the writer that microalgae will become viable as a biofuel food stock. The results from changing economic conditions and the social desire to address the world's environmental problems should increase the focus on such technologies. The changes must come from governments, business and the general community alike in order to preserve our planets well being and retain a livable environment.

Microalgae have existed on the planet for a very long time and may well play a major role in a changing world for a long time to come. I believe that the long term outlook of future energy sources is positive and microalgae may well play a big part of the resolving our day to day energy requirements. 


\section{References}

[1] Demirbas, A. and F. (2010) Algae Energy. Springer.

[2] Singh, N. and Dhar, D. (2010) Microalgae as a Second Generation Biofuel. Springer.

[3] Borowitzka, M. and Moheimani, N. (2012) Algae for Biofuels \& Energy. Springer.

[4] Seckbach, J. (2007) Algae and Cyanobacteria in Extreme Environments. Springer.

[5] Posten, C. and Posten, C. (2012) Micralgae Biotechnology. De Gruyter.

[6] Jayaraman, S.K. and Rhinehart, R.R. (2015) Modeling and Optimizing Algae Growth. School of Chemical Engineering, Oaklahoma State University.

[7] Gorden, R. and Seckbach, J. (2012) The Science of Algae Biofuels. Phycology, Geology, Biophotonics, Genomicsans and Nanotechnology. Springer. https://doi.org/10.1007/978-94-007-5110-1

[8] Bhatt, N., Panwar, A., Bisht, B. and Tamata, S. (2014) Coupling Algae Biofuel Production with Wastewater. Scientific World Journal, 2014, Article ID: 210504.

[9] Gourveia, R. (2011) Microalgae as Feedstock for Biofuels. Springer.

[10] Abodeely, J., Stevens, D., Ray, A., Schaller, K. and Newby, D. (2013) Algal Supply Design System. US Department of Energy.

[11] Lundquist, T., Woertz, I., Quinn, N. and Benemann, J. (2010) A Realistic Technology and Engineering Assessment of Algae Biofuel Production. Energy Biosciences Institute, University of California Berkley, California.

[12] UNESCO (2014) United Nations Educational, Scientific and Cultural Organization. World Water Day 2014 Advocacy Guide.

[13] Beca (2015) Opportunities for Renewable Energy in the Australian Water Sector Produced by Beca Consultants PTY LTD.

[14] Daily Mail (2015) Carbon Emissions Reach 40 Billion Ton High. www.dailymail.co.uk/sciencetech/article-276323/China-US-India-pushworld-carbo n-emissions-up.hmtl

[15] Bortowitza, M., Boruff, B., Moheinani, N., Pauli, N., Cao, Y. and Smith, H. (2012) Identification of Optimum Sites for Industrial Scale Microalgae Biofuel Production in WA Using GIS Model Algae. R \& D Centre Murdoch University, The School of Earth and Environment, University of Western Australia.

[16] Najafi, G., Ghobadian, B. and Yusaf, F. (2011) Algae as a Sustainable Energy Source for Biofuel Production in Iran: A Case Study. Elsevier.

[17] Boruff, B., Moheimani, N. and Borowitza, M. (2015) Identifying Locations for Large-Scale Microalgae Cultivation in Western Australia: A GIS Approach. Elsevier.

[18] Brune, D., Yen, H., Scharwtz, G., Benemann, J., Massingill, M., Van Olst, J. and Carlberg, J. The Control Eutrophication Process; Microalgae for Biofuel Production and Fertilizer Recycling at the Salton Sea, California. Clemson University, South Carolina.

[19] Alipour, H. and Tangal Olya, H. (2014) Sustainable Planning Model toward Reviving Lake Urmia. International Journal of Water Resources Development, 31, 519-539.

[20] Fortune (2015) Picking Winners in the Race to Iran. http://fortune.com/2015/08/25/business-opportunities-iran/

[21] Glen, E., Cohen, J., Morrison, J., Valdes-Casillas, C. and Fitzsimmons, K. (1999) Science and Policy Dilemmas in the Management of Agricultural Waste Waters: The Case of the Salton Sea, Ca, USA. Elsevier. 
[22] Western Australia Planning Commission (2009) Regional Profile Pilbara Framework. Western Australia Planning Commission.

[23] Jones, G. and Sanks, R. (2009) Pump Station Design. Elsevier.

[24] Yedidiah, S. (1996) Centrifugal Pump User Guide. Springer. https://doi.org/10.1007/978-1-4613-1217-8

[25] Brantes, L., Mendes, B. and Vermelho, A. (2013) Allelopathy as a Potential Strategy to Improve Microalgae Cultivation. BioMed Central Ltd..

[26] Weissman, J. and Goebel, R. (1987) Design \& Analysis of Microalgae Open Pond System for the Purpose of Producing Fuels. Solar Energy Research Institute.

[27] Gitelson, J. and Lisovsky, G. (2003) Man-Made Closed Ecological Systems. Taylor \& Francis.

[28] Moheimani, H., McHenry, M., de Boer, K. and Bahri, P. (2015) Biomass and Biofuels from Microalgae. Springer.

[29] Al Hattan, M., Ghaly, A. and Hammouda (2015) Microalgae Harvesting Methods for Industrial Production of Biodiesel. Fundamentals of Renewable Energy and Applications.

[30] Krisfopher, G. (2015) How Does the Production Cost of Crude Oil Affect Oil Prices. Market Realist.

[31] Tien, C. (2012) Principles of Filtration. Elsevier.

[32] Goa, Y., Gregor, C., Liang, Y., Tang, D. and Tweed, C. (2009) Algae Biodiesal, a Feasibility Report.

[33] Asian Development Bank (2011) Asian Solar Development Initiative. Asian Development Bank.

[34] Solar Farm Feasibility Study (2013) District Council of Mount Remarkable. IT Power Pty Ltd.

[35] Bachus, L. and Custodio, A. (2006) Know and Understand Centrifugal Pumping. Elsevier.

[36] Iran Geography (2015) Iran History Foreign Media Service in Iran.

[37] Regional Development Australia Pilbara Committee (2013) Pilbara State of Environment Report 2013. Shire of Ashburton, Town of Port Hedland \& Shire of Roebourne.

[38] Europe Pump \& Hydraulic Industry (2004) Variable Speed Pumping. Elsevier. 